\title{
Julmarichardiidae, a new apseudoidean family (Crustacea: Tanaidacea: Apseudomorpha) with the description of a new species of Julmarichardia Guţu, 1995 from the Northwest Australian Shelf
}

\author{
ANDRES G. MORALÉS-NÚÑEZ ${ }^{*}$ \& RICHARD W. HEARD ${ }^{2}$ \\ ${ }^{1} N S F-C R E S T$ Center for the Integrated Study of Coastal Ecosystem Processes and Dynamics in the Mid-Atlantic Region (CISCEP), \\ Department of Natural Sciences, University of Maryland Eastern Shore, Princess Anne, MD 21853, USA \\ ${ }^{2}$ Department of Coastal Sciences, University of Southern Mississippi, Gulf Coast Research Laboratory Campus, Ocean Springs, MS \\ 39564, USA. \\ ${ }^{*}$ Corresponding author." agmorales@umes.edu; @ ittps://orcid.org/0000-0003-3604-5991
}

\begin{abstract}
A new tanaidacean family Julmarichardiidae is designated to receive the Indo-Pacific genus Julmarichardia Guţu. The new family is characterized by having a prominent rostrum, a strongly developed coxal process of pereopod-1 with plumose setae and sometimes spines, and the presence of mucus glands and packets throughout its body. The latter appear to be involved in the construction of a mucus domicile. Based on distinctive antennal and pereopodal characters, the South China Sea species, J. bajau Bamber \& Sheader, is placed in a new monotypic genus. A second Australian species is described from specimens collected on the northwestern continental shelf from depths of 37 to $83 \mathrm{~m}$. The new species can be distinguished from its sympatric congener $J$. gutui Ritger \& Heard by a variety of characters, including the lack of setulose setae on the rostral margin and the posterior margin of pereopod-1 having three or fewer setulate setae. It differs from J. alinati Guţu, by the shape and/or spination of the rostrum, antennule, and antenna. Julmarichardia dollfusi (Guțu) is removed from Julmarichardia and designated as Metapseudidae incertae sedis. A key to the six species comprising the genus Julmarichardia is presented.
\end{abstract}

Key words: Richardjulmaia, Julmarichardia magdae, Julmarichardia sp. A, new family, new genus, taxonomy, NW Australian Continental Shelf

\section{Introduction}

The genus Julmarichardia Guţu, 1989 was established to receive three species, J. alinati Guţu, 1989 and $J$. thomassini Guţu, 1989 from Mozambique, and J. (=Apseudes) deltoides (Barnard, 1914) from the southeastern coast of South Africa (Guţu 1989a). Julmarichardia is the only genus within the family Metapseudidae Lang, 1970 having a pereopod-1 with a well-developed, coxal process (Guţu 1989a; Heard et al. 2004) — a main feature that was not included by Guţu (1989a) in the original diagnosis of the genus. Later, J. bajau Bamber \& Sheader, 2005 and $J$. gutui Ritger \& Heard, 2007 were described from the waters of the Malaysian and Northwest Australian Continental Shelves, respectively. More recently, Guţu (2014) transferred Calozodion dollfusi Guţu, 1989 (described from a single manca), from the cold temperate waters of the northeastern Atlantic, to Julmarichardia.

Ritger \& Heard (2007) described Julmarichardia gutui based on specimens from benthic samples collected from depths of 78 to $83 \mathrm{~m}$ on the Northwest Australian Continental Shelf. During part of this same baseline study, but in shallower depths of 38 to $43 \mathrm{~m}$, a second distinct species of Julmarichardia was discovered among the tanaidacean material. The description of this undescribed species and the designation of a new family to accommodate the genus Julmarichardia are presented here. 


\title{
Material and methods
}

The material examined during this work was collected by the Research Vessel (RV) Soela during a baseline study conducted by Commonwealth Scientific and Industrial Research Organization (CSIRO) on the Northwest Australian Continental Shelf during 1983-1984 (Fig. 1). Furthermore, topotypical specimens of Julmarichardia gutui (Ritger \& Heard, 2007) were revised.

Specimens were dissected under an Olympus SXZ16 stereomicroscope. Appendages were mounted on glass slides in glycerine and observed with an Olympus BX41 compound microscope, and drawings were made with a camera lucida. Illustrations were prepared with Adobe Illustrator CC 2020 and figures with Adobe Photoshop CC 2020. Photographs were taken using an Olympus DP73 digital camera mounted on a stereomicroscope and/ or compound microscope and all specimens were measured with CellSens Dimension 1.11 Imaging Software (Olympus). Maps were created using ArcGIS 10.4.1 software (University of Maryland Eastern Shore (UMES))

All specimens of the new Julmarichardia species were measured and separated into several life-stages categories: 1) non-ovigerous females - with oostegites, 2) ovigerous females - carrying embryos in the marsupium, 4) females with marsupium - carrying empty marsupium, 4) male - with chelipeds most robust and penial cone.

Type material is deposited in the Australian Museum, Sydney (AM), National Museum of Natural History, Smithsonian Institution, Washington, DC (USNM), and Gulf Coast Research Laboratory (GCRL). All measurements were taken in millimetres (mm). Total body length (TBL) was measured from the tip of the rostrum to the tip of the pleotelson. Terminology generally follows that of Larsen (2003); however, the abbreviation "PSS", plumose sensory seta, here referring to the basally buttressed, small, delicate sensory seta(e) bearing fine setules. These setae occur on antennules, antennae, pereopods, and uropods (Bird 2011).

\begin{abstract}
Abbreviations
RV: research vessel; CSIRO: Commonwealth Scientific and Industrial Research Organization; AM: Australian Museum, Sydney; USNM: National Museum of Natural History, Smithsonian Institution, Washington DC; GCRL: Gulf Coast Research Laboratory; TBL: Total body length; Stn: Station; SA: subadult(s); PSS: plumose sensory seta(e); NW: Northwest.
\end{abstract}

\section{Systematics}

\section{Superfamily Apseudoidea Leach}

\section{Family Julmarichardiidae fam. nov.}

Type genus. Julmarichardia Guţu, 1989

Diagnosis. Antenna with squama. Rostrum well-developed spatulate or triangular, margins with or without spines or spinules, and with or without plumose setae. Cheliped and pereopod-1 with exopod. Pereopod-1 with strongly developed coxal process dorsal margin bearing plumose setae and with or without spines. Mucus glands and reservoir packets dispersed throughout body and appendages with ducts opening on dactylus of pereopod-1. Pleon unfused, with five pairs of well-developed biramous pleopods.

Etymology. From the double-patronym, type-genus, Julmarichardia.

Remarks. Julmarichardiidae fam. nov. and the Numbakullidae Guţu \& Heard, 2002, are both small highly derived families, both of which are presently known from the Southwest Pacific and Indian Ocean. Based on the morphology of their appendages, primarily the pereopods, and other meristic features, both appears to have evolved from the same progenitors that gave rise to the family Metapseudidae Lang, 1970. These two small families, unlike members of the larger, more diverse, and widely distributed Metapseudidae, are characterized by the presence of mucus glands and reservoir mucus packets throughout their bodies and appendages.

Like the julmarichardiids, numbakullids are represented by a single genus and a few (three) species (Stępień 2013); they are unique by having dense rows of long plumose setae on the posterior margins of the merus and carpus on pereopod-1 (Guţu \& Heard 2002: figs 1B, 3C). These setal modifications, which immediately distinguished numbakullids from the julmarichardiids and the metapseudids, appear to be an adaptation to facilitate suspension and/or filter feeding (Ibid) and maybe analogous to that of the kalliapseudids. 


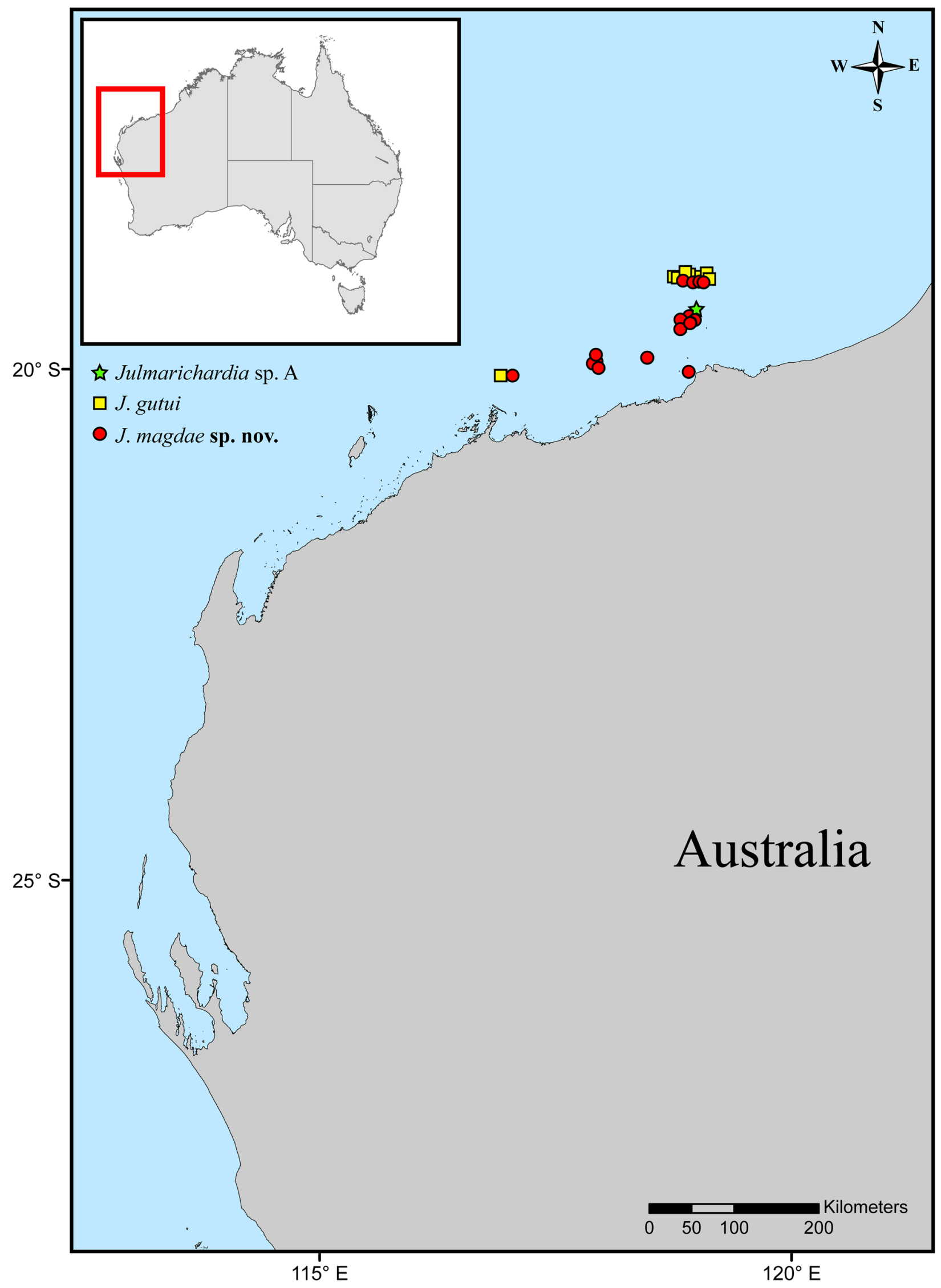

FIGURE 1. Map of study area, indicating the sampling stations where Julmarichardia magdae sp. nov., J. gutui, and J. sp. A. were recorded. 
The distinctive presence of mucus glands, a prominent anteriorly-directed coxal process on pereopod-1, and a strongly developed broad rostrum distinguish Julmarichardiidae from the Metapseudidae, where it (the genus) was originally placed by Guţu (1989a). Except for these distinctive differences, the general morphology of Julmarichardiidae appears to be most similar to that of the metapseudid Subfamily Chondropodinae Guţu, 2008. Both groups share several apparent plesiomorphic characters, including the presence of an antennal squama, exopods on the cheliped and pereopod-1, and unfused pleonites bearing five pairs of well-developed pleopods. As mentioned earlier, these similarities indicate that the two groups may have been derived from the same ancestral stock.

Besides the Julmarichardiidae and Numbakullidae, only two other apseudomorphan families, the Kalliapseudidae Lang, 1956 and Parapseudidae Guţu, 1981 (see Drumm 2005; Kakui \& Hiruta 2014, 2017; Morales-Núñez et al. 2017) are known to have distinct mucus glands. The mucus produced by these glands is used, at least in part, in the construction of domiciles (Drumm 2005; Morales-Núñez et al. 2017; Heard et al. 2018). One of us (RWH) when initially sorting tanaidaceans samples from the NW Australian Shelf observed remnants of mucoid domiciles still attached to specimens of both Julmarichardia gutui and Numbakulla pygmaeus Guţu \& Heard, 2002. Whether the mucus glands occurring in the representatives of these two small Indo-Pacific families are homologous or have been derived independently remains to be determined.

\section{Genus Julmarichardia Guţu, 1989}

Type species. Julmarichardia alinati Guţu, 1989

Species. Julmarichardia alinati; J. bajau, J. deltoides; J. gutui; J. thomassini; J. magdae sp. nov.; J. sp. A.

Diagnosis. As for family.

Remarks. At our request, Modest Guţu reexamined the type material of Julmarichardia alinati, a male allotype and female paratype, and for J.thomassini, an incomplete male allotype, deposited in the Collections of the "Grigore Antipa" National Museum of Natural History, Bucharest. He was able to confirm the presence of mucus packets on the males of both species; however, mucus packets were not observed on the appendages of the female of $J$. alinati, due to the strongly chitinized surface of the appendages and by being covered with numerous acicular crystals. Mucus packets were observed in the male of the J. alinati on both chelipedal fixed finger, and carpus and propodus of the pereopods 1-2 and 6, and in the incomplete male of $J$. thomassini on the fixed finger of the chela, and carpus and propodus of the pereopods 1-2. Furthermore, based on reexamination of topotypical material of $J$. gutui, the presence of mucus packets was also observed on several appendages (M. Guţu, per. com. 2018). Mucus appears to be processed and extruded by a specialized structure located in the propodus of pereopod- 1 and appears to be released through an opening located on the inner face of the propodus (see Fig. 8C). The presence of mucus glands in Julmarichardia deltoides and J. bajau has not been confirmed but given their other generic features their presence is strongly suspected. Pending their reexamination, we have included presence of mucus glands as part of the modified generic and new family diagnoses.

With these new observations, the presence of mucus glands and packets is now documented for five of the six recognized species of Julmarichardia. One species $J$. deltoides needs to be reexamined for their presence (Table $1)$.

TABLE 1. Alphabetical listing of the six currently recognized species for the genus Julmarichardia including information on mucus gland, distribution, and depth range.

\begin{tabular}{llll}
\hline Species & Mucus glands & Geographical area & Depth range (m) \\
\hline alinati Guţu 1989 [type species] & Present & South western Indian Ocean (Mozambique) & $6-450$ \\
deltoides (Barnard, 1914)* & Undetermined & South western Indian Ocean (South Africa) & 90 \\
gutui Ritger \& Heard, 2007 & Present & South eastern Indian ocean (Australia) & $52-86$ \\
magdae sp. nov. & Present & South eastern Indian ocean (Australia) & $37-83$ \\
thomassini Guțu, 1989* & Present & South western Indian Ocean (Mozambique) & 250 \\
sp. A* & Present & South eastern Indian ocean (Australia) & 54 \\
\hline
\end{tabular}

* Indicates male unknown. 
The taxonomic status of Calozodion dollfusi Guţu, 1989 is uncertain. He described this species based on a single manca stage collected from the cold-temperate northeastern Atlantic waters off Jersey, one of the Channel Islands. Later he (Guţu 2014) transferred this species to the genus Julmarichardia. However, based on the original description of $C$. dollfusi, we do not believe that it can be referred to Julmarichardia with any degree of confidence. Characters of $C$. dollfusi that include (1) an antenna with basal article entire (not dentate), (2) rostrum forming a broad rounded dentate frontal margin (remnants of some species of Calozodion, but not Julmarichardia), and (3) pereopod-1 with coxal process not greatly pronounced anteriorly and the anterior margin of the basis lacking spiniform processes, diminish the possibility that this species is referrable to Julmarichardia. Other characters exhibited by $C$. dollfusi do not appear to be exclusively related to those attributed to the other nominal species of Julmarichardia, all of which are currently known only from the southern Indo-Pacific and immediately adjacent waters. Further, zoogeographically, the occurrence of "Julmarichardia dollfusi" in the cold-temperate waters of the NE Atlantic (49.2 $\left.{ }^{\circ} \mathrm{N}, 2.1^{\circ} \mathrm{W}\right)$ is far removed from the other nominal warm-water Indo-Pacific species of the genus. Pending the discovery of adult topotypical material, Calozodion dollfusi is here considered "Metapseudidae genus inquirenda."

When comparing species of Julmarichardia described from the Indo-Pacific, Julmarichardia bajau, which is known from the eastern margin of the Indian Ocean (Malaysia), differs markedly from its East African and Australian congeners. These differences involve distinct meristic differences in the antenna, maxilliped, and pereopods of $J$. bajau. Based on these morphological differences and circumstantially supported by its physical and apparent temporal distance from other known members of the genus, we here place J. bajau in a new genus.

\section{Richardjulmaia gen. nov.}

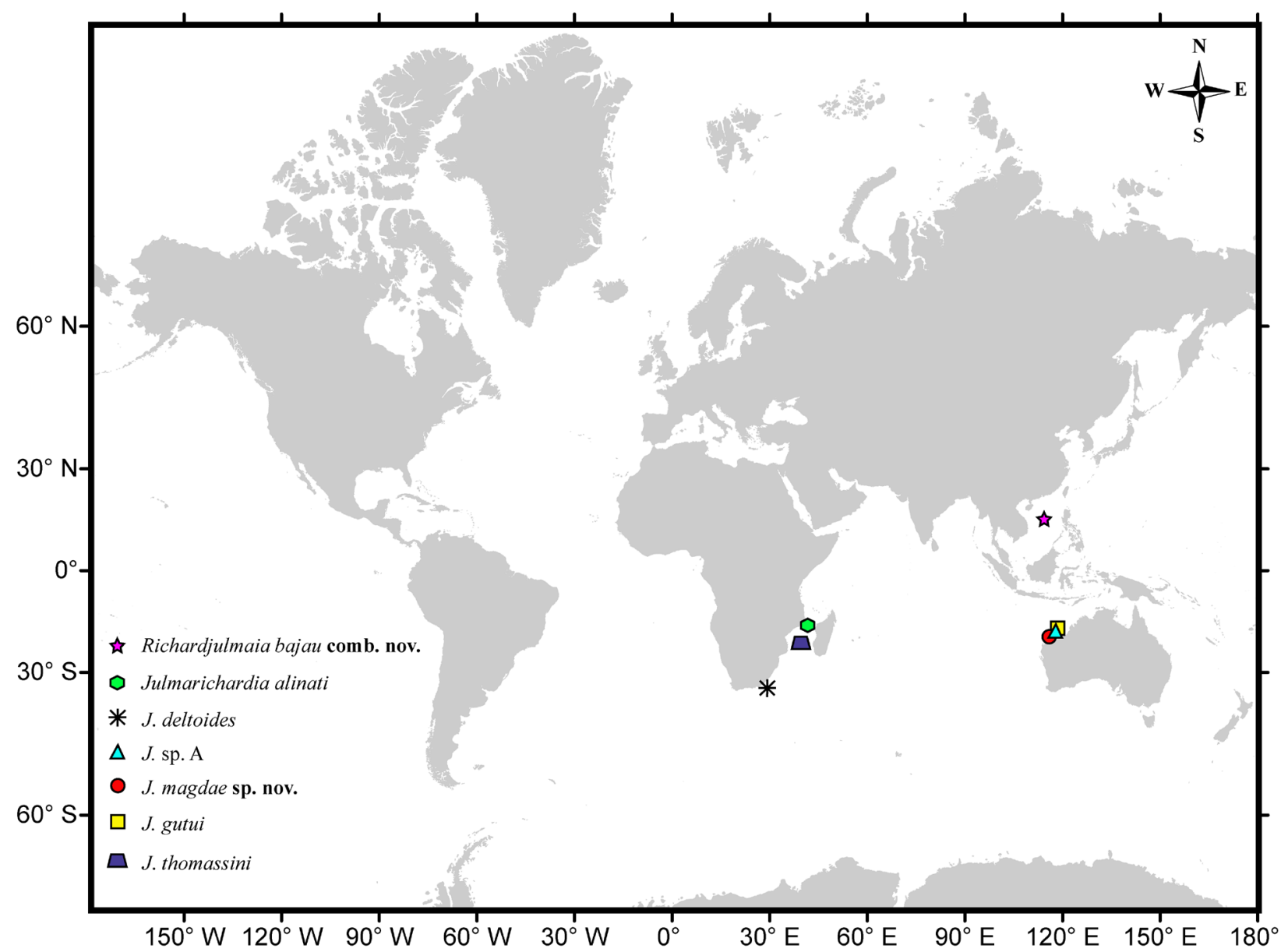

FIGURE 2. Map showing the worldwide distribution of Richardjulmaia and Julmarichardia. Richardjulmaia bajau comb. nov. (magenta star), Julmarichardia alinati (green polygon), J. deltoides (black asterisk), J. sp. A (cyan triangle), J. magdae sp. nov. (red circle), J. gutui (yellow square), and J. thomassini (purple trapezoid). [Data from: Guţu (1989); Bamber \& Sheader (2005); Barnard (1914); Ritger \& Heard (2007); Morales-Núñez \& Heard (this study)] 
Diagnosis. Female. Antenna with lateral and inner margins entire (not dentate). Maxilliped palp article-1 having lateral margin with sub-distal, setulate seta.

Male unknown

Type species. Richardjulmaia bajau, Bamber \& Sheader, 2005 comb. nov.

Etymology. Generic name derived from the double patronym of Julmarichardia, but with the order reversed.

Gender. Masculine.

Distribution. Shallow waters of Sabah, Malaysia (Fig. 2).

\section{Julmarichardia Guţu, 1989}

Diagnosis. Female. Antenna with lateral and inner margins distinctly dentate. Maxillipedal palp article-1 having lateral margin with spiniform seta.

Male. Cheliped much larger and robust than that of female.

Type species. Julmarichardia alinati Guţu, 1989.

Species. J. alinati; J. deltoides; J. gutui; J. thomassini; J. magdae sp. nov.; J. sp. A.

Distribution. Southwestern and southeastern Indian Ocean (Fig. 2).

\section{Julmarichardia magdae sp. nov.}

(Figs 3-19; 20G, M, O)

Material examined. Type material. Holotype -non-ovigerous $q$ (with oostegites), TBL $3.4 \mathrm{~mm}$, (AM P.52337), Station (Stn) 01-B9-S, (19²8'00”'S; -118 55'.00”E), depth 38 m, Coll: FRV “Soela", CSIRO 12-Feb-1983.

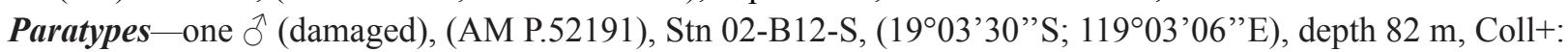
FRV "Soela", CSIRO 28-Apr-1983.—one SA, one non-ovigerous + (with oostegites), and one ${ }^{\lambda}$, (AM P.52203), Stn 04-B13-S, (1948'48”S; 11752'12”'E), depth 52 m, Coll: FRV “Soela”, CSIRO 02-Sep-1983.- two nonovigerous 우우 (with oostegites), three ovigerous 우우, one $\widehat{\partial}$ (damaged), and two undetermined, (AM P.52327), Stn 04-B16-S, (2001'12"S; 11657’36”E), depth 52 m, Coll: FRV “Soela”, CSIRO 04-Sep-1983. —one nonovigerous $q$, one ovigerous $q$, and one $\delta$ (TBL $3.3 \mathrm{~mm}, 3.3 \mathrm{~mm}$, and $2.5 \mathrm{~mm}$, respectively; USNM 1659739); one non-ovigerous $q$, one ovigerous $q$, and one $\delta$ (TBL $3.1 \mathrm{~mm}, 3.4 \mathrm{~mm}$, and $2.4 \mathrm{~mm}$, respectively; GCRL 06610); eight non-ovigerous $q$, ten $\widehat{\partial} \widehat{\partial}$, and 15 undetermined (AM P.105698), same collection data as holotype.- two

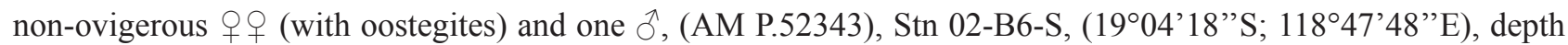
83 m, Coll: FRV “Soela”, CSIRO 27-Apr-1983.- - eleven non-ovigerous $ㅇ+$ (with oostegites), two ovigerous $ㅇ+$, $13 \hat{\partial} \hat{\partial}$, and 15 undetermined, same collection data as holotype.- three non-ovigerous $+q+$ (with oostegites), four

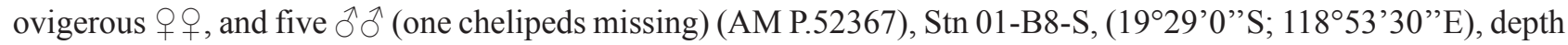
40 m, Coll: FRV "Soela", CSIRO 12-Feb-1983.--three SA, 20 non-ovigerous $q 9$ (with oostegites), five ovigerous

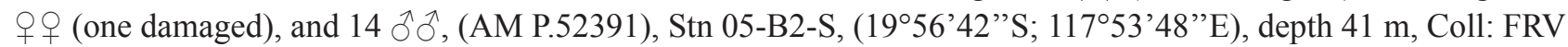

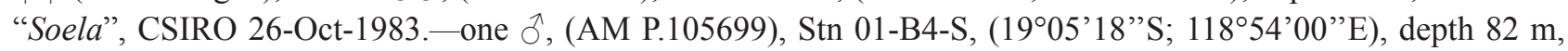
Coll: FRV "Soela", CSIRO 15-Feb-1983.- one SA, 14 non-ovigerous $q$ + (with oostegites), six ovigerous $q$, , two

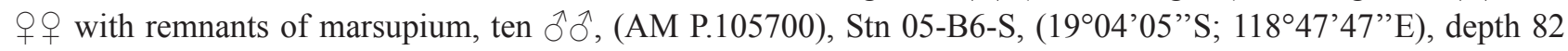
m, Coll: FRV "Soela", CSIRO 30-Oct-1983. .--three SA, 17 non-ovigerous $q$ ( (with oostegites), two ovigerous

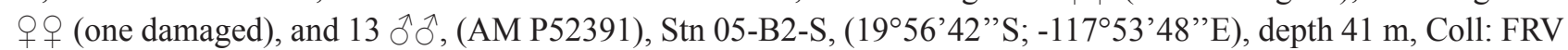
"Soela", CSIRO 26-Oct-1983.--one SA, three non-ovigerous 우우 (with oostegites), one $\widehat{\delta}$ (TBL $2.5 \mathrm{~mm}$, very good condition), and one undetermined (broken), (AM P.105704), Stn 01-B10-S, (1905'12”S; -118 57'36”E), depth 82 m, Coll: FRV "Soela", CSIRO 14-Feb-1983.- - one non-ovigerous + (with oostegites) and one ovigerous

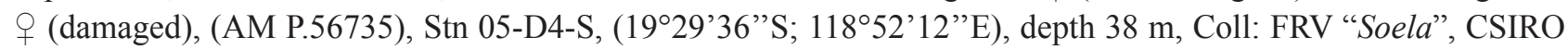
25-Oct-1983.- - three SA, four non-ovigerous $q$ 우 (with oostegites), three ovigerous $q$ 우, and three $\hat{\jmath} \hat{\delta}$, (AM P.56739), Stn S05-B1-5, (1959'00"S; 117051'06”E), depth 41 m, Coll: FRV “Soela”, CSIRO 26-Oct-1983.-five ovigerous + 우, seven $\partial^{\lambda}$, and 13 undetermined (one broken and 12 (partially dried out)), (AM P.56753), Stn 05D1-S, (19²9'54”S; 11852'00”E), depth 37 m, Coll: FRV “Soela”, CSIRO 24-Oct-1983.

Diagnosis. Female. Antennule with outer flagellum of eight or fewer articles. Rostrum with rounded tip, with 
$\sim 22$ or more small, blunt marginal denticles of varying sizes, lacking plumose setae. Left mandible lacinia mobilis with six denticles (Table 2).

TABLE 2. Comparison of morphological features of the six currently recognized species of the genus Julmarichardia.

\begin{tabular}{llll}
\hline Species & $\begin{array}{l}\text { Rostrum with denticles, } \\
\text { plumose setae, or smooth }\end{array}$ & $\begin{array}{l}\text { No. of antennular articles } \\
\text { on outer flagellum }\end{array}$ & $\begin{array}{l}\text { No. of denticles on lacinia } \\
\text { mobilis }\end{array}$ \\
\hline J. alinati [type species] & Denticles & 7 & 3 \\
J. deltoides & Denticles & 12 & 1 \\
$J$. gutui & Plumose setae & 6 & 3 \\
$J$. magdae sp. nov. & Denticles & 8 or fewer & 6 \\
$J$. thomassini & Denticles & 11 & 4 \\
$J$. sp A & Smooth & 8 & $*$ \\
\hline
\end{tabular}

* Not determined.

Male. Cheliped propodus with five bipinnate spiniform setae on mid-medial margin near articulation of dactylus. Rostrum with rounded tip subacute. Pereonites $4-5$ with hyposphenia. Hyposphenia present on all pleonites.

Etymology. The species is named in honor of Magdalena Błażewicz in recognition of her significant contributions to the taxonomy and systematics of the order Tanaidacea.

Type locality. Northwest shelf $\left(19^{\circ} 28^{\prime} 00^{\prime \prime} \mathrm{S} ; 118^{\circ} 55^{\prime} .00^{\prime \prime} \mathrm{E}\right)$ of Australia.

Distribution. Known only from the type locality at depths ranging from 37 to $83 \mathrm{~m}$.

Description. Based on non-ovigerous + (with oostegites). Body (Fig. 3A). Dorso-ventrally flattened, TBL 2.9 $\mathrm{mm}$, about 4.2 times width.

Cephalothorax (Fig. 3A). About $\sim 25 \%$ of TBL, as long as wide, shorter than combined lengths of pereonites 1-3; rostrum well-developed, spatulate, deflected anteroventrally, margins and tip armed with small denticles and lacking setulate setae; eye-lobes well-defined, pointed, with visual elements present. Carapace with two rows of small spines at base of rostrum, with small denticles at bases of antennule (Fig. 3A-B), with six pairs of setulate setae of unequal lengths along mid-dorsal margin, with one plumose seta on the mid-lateral margin.

Pereon (Fig. 3A). About $55 \%$ of TBL, all pereonites wider than long, each with antero-posterior lateral margins having very small denticles; pereonite-1 widest; pereonite-4 longest; pereonite-6 shortest; pereonites 1-6 each with one to three setulate setae on proximal and distal margins; pereonites 1-5 with two small, setulate or simple setae mid-dorsally.

Pleon (Fig. 3A, C). About $\sim 15 \%$ of TBL, combined lengths of pleonites 1-5 longer than pereonites 5-6; all pleonites sub-equal, wider than long, bearing pleopods; each pleonite with anterior-dorsal margin having a row of very small denticles (visible in lateral view, not illustrated); each pleonite with lateral margins armed with denticulate triangulate-like lateral process bearing several plumose setae at or near apex; each pleonite with plumose seta on lateral margins; pleonites 1-4 with four (two proximal and two distal) small simple setae on mid-dorsal margin; pleonite-5 with two plumose setae on disto mid-dorsal margin.

Pleotelson (Figs 3A, C-E, 16A-C). About $~ 5 \%$ of TBL, longer than pereonite-6 (Fig. 3A), weakly pointed at apex (Figs 3A, 16A), anterior dorsal margin with row of five small simple setae, with two rows each of one plumose and three simple setae mid-dorsally on posterior margin, with small, dorsal, sub-distal simple seta adjacent to each uropodal insertion site (Fig. 3A); antero-lateral margin with narrow apophysis bearing single plumose seta distally, and small postero-lateral apophysis bearing two plumose setae (Fig. 3C); mucus packets adjacent to antero-lateral apophysis and mid margin (Fig. 16A-C), mucus packets occurring below ventral margin (Fig. 16B-C), with two simple setae on mid posterior margin (Fig. 3D), with two sub-distal small simple setae close to the insertion with uropod at each site (Fig. 3D).

Antennule (Figs 4A, 14A). Peduncle with four articles. Article-1 about 5.1 times longer than wide, with mucus packets in article-1 (Fig. 14A); inner margin with nine translucent acute or subacute apophyses of varying lengths, with six plumose setae; distal medial margin with two plumose setae; outer margin with acute short mid-marginal translucent apophyses and long distal translucent sub-acute apophyses, having proximal clusters of two and three PSS, two PSS, and long simple seta sub-distally. Article-2 about 1.9 times longer than wide; inner margin with subproximal simple seta and sub-distal plumose seta; distal media margin with two (one long) simple setae and two 
PSS; outer distal margin with cluster of three PSS. Article-3 about 2.4 times longer than wide; inner distal margin with two PSS and long simple seta; outer distal margin with long simple seta. Article-4 (common) shorter than broad; medial distal margin with row of five PSS. Outer flagellum having eight articles/pseudo-articles, each with simple seta on inner distal margin and 1-2 simple setae on outer distal margin. Articles 3, 5, 7 and 8 with aesthetascs. Inner flagellum with five articles/pseudo-articles. Article-1 small, asetose. Article-2 with three distal simple setae. Article-3 asetose. Article-4 with simple distal seta. Article-5 with two distal simple setae.

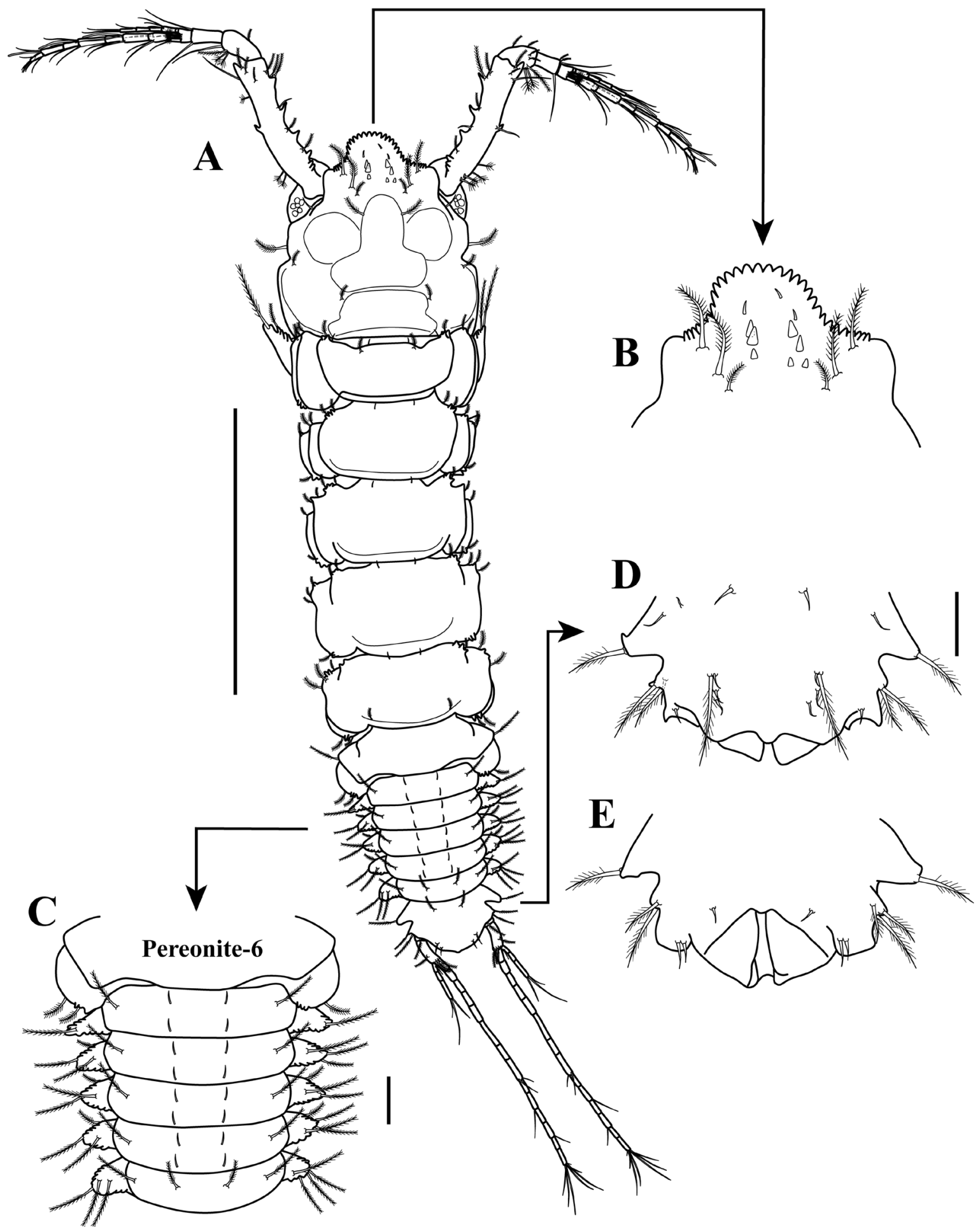

FIGURE 3. Julmarichardia magdae sp. nov. paratype non-ovigerous female. A, dorsal view; B, enlargement of rostrum; C, enlargement of pereonite- 6 and pleonites 1-5, dorsal view; D, enlargement of pleotelson, dorsal view; E, enlargement of pleotelson, ventral view. Scale bars $=1.0 \mathrm{~mm}$ for A and $0.1 \mathrm{~mm}$ for $\mathrm{C}-\mathrm{E}$. 


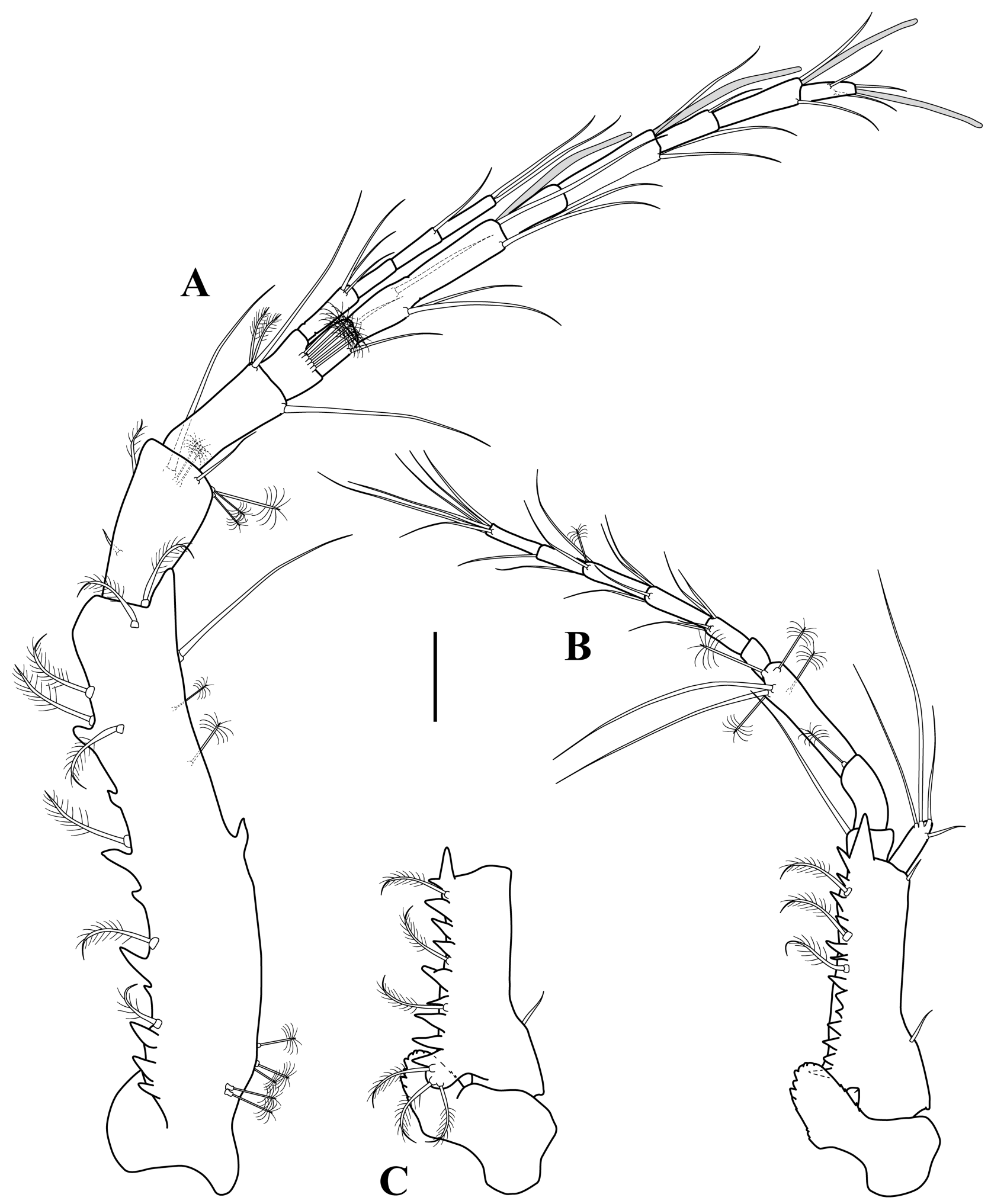

FIGURE 4. Julmarichardia magdae sp. nov. paratype non-ovigerous female. A, antennule, outer view; B, antenna, inner view; C, antennal articles $1-2$, ventral view. Scale bar $=0.1 \mathrm{~mm}$.

Antenna (Figs 4B-C, 14B). With eleven articles, distinctly shorter than antennule, with mucus packets in article2 (Fig. 14B). Article-1 with prominent spatulate process on inner margin, with distal denticles. Article-2 about 4.3 times longer than wide; inner dorsal margin with $\sim 14$ translucent acute or subacute apophyses of varying lengths and three plumose setae (Fig. 4B); inner ventral margin with proximal rounded process (beneath the spatulate 
process of article-1) bearing three plumose setae (Fig. 4C), with $\sim$ ten translucent acute or subacute apophyses of varying lengths, and three plumose setae (Fig. 4B); outer dorsal margin with sub-proximal and distal simple seta; squama present, longer than article-3, with four distal simple setae of varying lengths. Article-3 wider than long, inner distal margin with long simple seta. Article-4 about 2.2 times longer than wide; medial distal margin with PPS. Article-5 about 4.5 times longer than wide, longer than article 3-4 combined; inner margin with two long simple setae and PSS; medial distal and sub-distal margins with three PSS. Article-6 short, asetose. Article-7 about 2.6 times longer than wide; each inner and outer margin with two distal simple setae. Article-8 about 3.9 times longer than wide; inner distal margin with simple seta; medial distal margin with simple seta; outer distal margin with two simple setae. Article-9 same length than article-8; inner distal margin with simple seta; medial distal margin with simple seta; outer distal margin with simple seta and PSS. Article-10 about 2.7 times longer than wide; inner distal margin with simple seta. Article-11 about 3.0 times longer than wide, with one sub-distal and five distal setae of varying lengths.

Clypeolabral complex (Fig. 5A). Clypeus simple, hood-shaped. Labrum (Fig. 5A). Subdivided in two parts by labral suture bearing fine setae, posterior $1 / 2$ bilobed with inner margins of lobes fringed with fine setae.

Mouthparts: Mandibles (Fig. 5B-I). Left mandible, incisor with four denticles (Fig. 5B), lacinia mobilis broad with six denticles, proximal-most denticle minute (Fig. 5C); setiferous lobe with four forked, distally expanded spatulate setae (Fig. 5B). Right mandible, incisor with four denticles (Fig. 5D-E), lacinia mobilis well-developed, distally expanded, bifurcate (Fig. 5D-F), setiferous lobe with five forked, distally expanded spatulate setae (Fig. 5D). Molar process of left and right mandible similar, with grinding surface with well-developed micro-denticles and simple setae (Fig. 5B, D). Palp (Fig. 5G-I) article-1 about 2.1 times longer than wide, inner margin with eight setulose spiniform setae, longest occurring distally; article-2 longest, about 2.6 times longer than wide, mid-inner margin with eleven setulate setae of unequal lengths (Fig. $5 \mathrm{H}$ ); article-3 shortest, mid-inner margin with cluster of four setulate setae and seven sub-distal and distal setulate setae of different lengths (Fig. 5I), with terminal setae being longest.

Labium (Fig. 5J). Lobe with inner distal margin setose, with several small "saw-like" spinules. Palp conical, inner margin setulose; outer margin setulose, with two sub-proximal spines; with three distal spiniform setae.

Maxillule (Fig. 6A-B). Inner endite with five setulate distal setae, outer margin of inner endite finely setose with sub-proximal tubercle. Outer endite with eleven distal spiniform setae, at least four of them with mid-inner denticulate margin (Fig. 6B), and two sub-distal setulate setae, margins finely setose (setae longer on outer margin); palp biarticulated terminating in three long (two sub-distal and one distal) setae, having tip armed with minute recurved spinules.

Maxilla (Fig. 6C-J). Inner and outer margins finely setose; outer lobe of movable endite with two long inner pinnate-inner setulose spiniform setae (Fig. 6D) and seven slightly shortest inner pinnate spiniform setae (Fig. 6E); inner lobe of movable endite with seven inner pinnate-inner setulose spiniform setae (Fig. 6F); outer lobe of fixed endite with four simple setae, two bipinnate-plumose spiniform setae (Fig. 6G), and three trifurcate-plumose spiniform setae (Fig. 6H); inner lobe with five outer bipinnate-outer setulose spiniform setae (Fig. 5I), and with $\sim 21$ basally swollen setae with bifid tip, sub-terminally (Fig. 5J).

Maxilliped (Fig. 6K-N). Coxa short and wide. Basis longer than wide, inner sub-distal margin with three welldeveloped setulate setae, outer distal margin with denticles. Palp (Fig. 6K) article-1 shortest, inner margin finely setulose with sub-distal setulose setae, outer margin about twice as wide as inner, attenuated forming large lateral spine; article-2 largest, widest distally, inner margin with five setulate setae of varying lengths and row of nine curved simple setae along distal half, outer distal margin with strongly developed spine; article- 3 widest in proximal half, inner margin with ten well developed, long, slightly down-curved, setulose setae; article-4 inner margin with seven bipinnate setae and simple seta. Endite (Fig. 6L-N) inner margin having three coupling hooks, row of eight basally-swollen setulate setae, with sub-distal bipinnate spiniform seta, five apically bidentate or grooved spiniform setae with outer setulose margin (Fig. 6M), increasing size distally, with four outer setulose spiniform setae (Fig. $6 \mathrm{~N})$, outer margin setulose.

Epignath (not illustrated). Broad, irregularly suboval, terminal seta setulate.

Cheliped (Figs 7A-I, 14C). Exopod with three articles, third article bearing four plumose setae. Mucus packets in carpus, propodus, and dactylus (Fig. 14C). Basis about 1.4 times longer than wide; ventral margin with spiniform seta on mid-margin (missing in right cheliped (Fig. 7A) but present in left cheliped (Fig. 7B)), and five sub-distal plumose setae; inner face with mid-dorsal margin crenulate, with two mid-medial and two mid-dorsal simple setae 


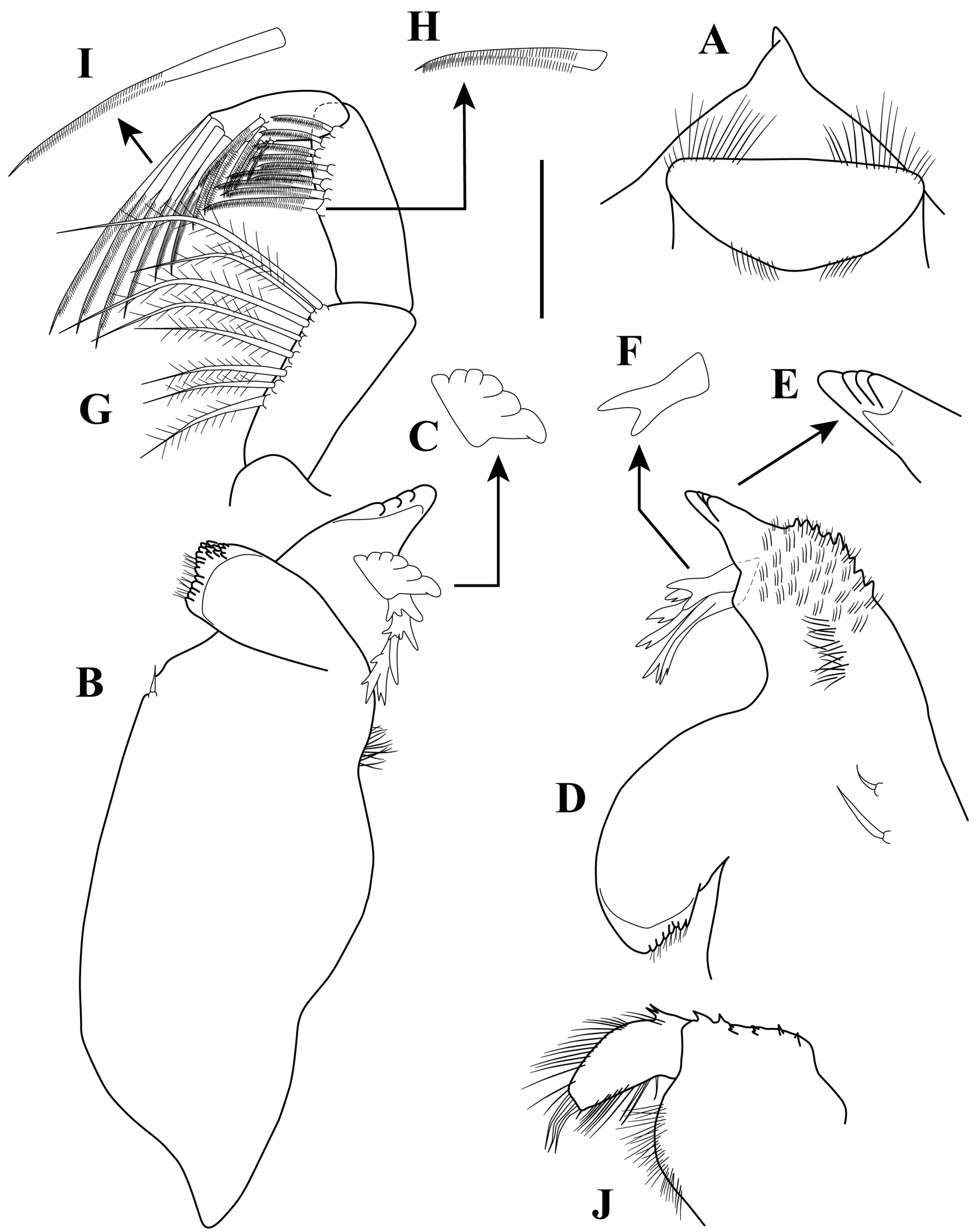

FIGURE 5. Julmarichardia magdae sp. nov. paratype non-ovigerous female. A, labrum; B, left mandible; C, enlargement of left lacinia mobilis; D, right mandible; E, enlargement of incisor; F, enlargement of right lacinia mobilis; G, mandible palp; H, enlargement of setulate spiniform seta; I, enlargement of setulate spiniform seta, J, labium. Scale bar = 0.1 mm for A-B, D, G, and $\mathrm{J}$. 


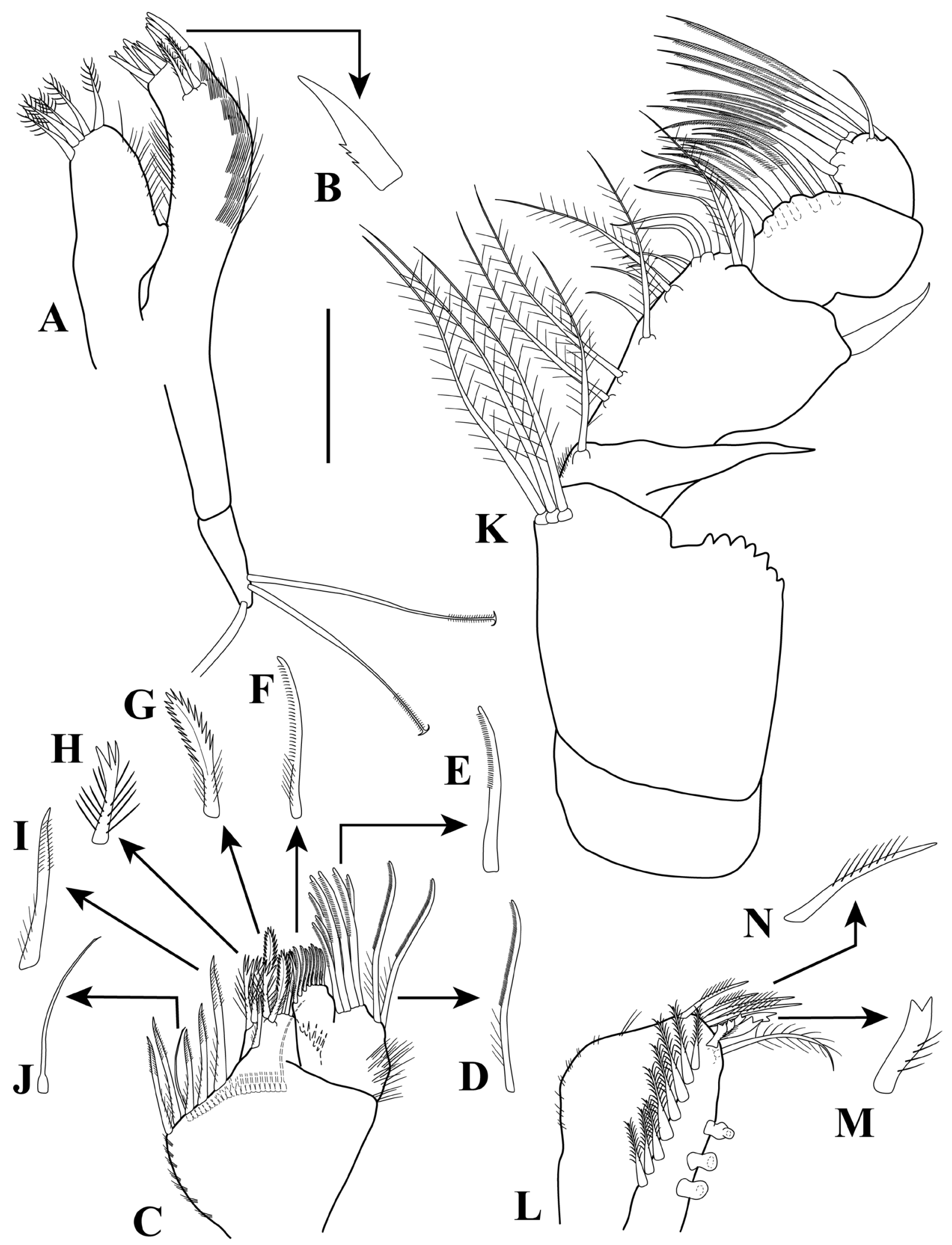

FIGURE 6. Julmarichardia magdae sp. nov. paratype non-ovigerous female. A, maxillule; B, enlargement of mid-inner denticulate spiniform seta; C, maxilla; D, enlargement of inner pinnate-inner setulose spiniform seta; E, enlargement of inner pinnate spiniform setae; F, enlargement of inner pinnate-inner setulose spiniform setae; G, enlargement of bipinnate-plumose spiniform setae; H, enlargement of trifurcate-plumose spiniform setae; I, enlargement of bipinnate-outer setulose spiniform setae; J, enlargement of swollen seta with bifid-tip; K, Maxilliped; L, endite; M, enlargement of apically bidentate or grooved spiniform setae with outer setulose margin; $\mathrm{N}$, enlargement of outer setulose spiniform setae. Scale bar $=0.1 \mathrm{~mm}$ for A, C, K-L. 


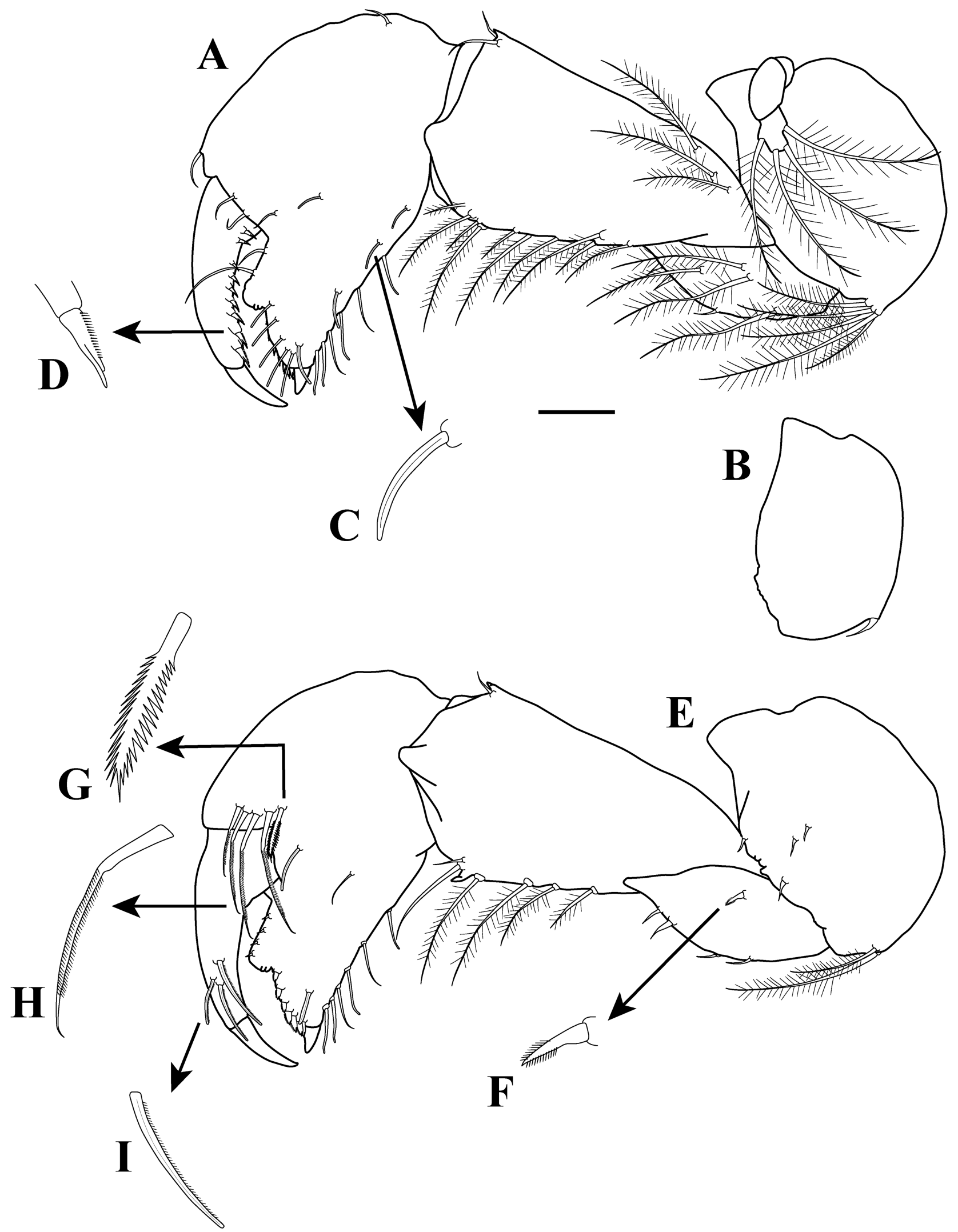

FIGURE 7. Julmarichardia magdae sp. nov. paratype non-ovigerous female. A) right cheliped, outer view; B) left cheliped basis, outer view; C) enlargement of spiniform setae; D) enlargement of spine; E, right cheliped, inner view, F, enlargement of bipinnate spiniform setae; $\mathrm{G}$, enlargement of bipinnate spiniform seta; H, enlargement of inner setulate spiniform setae; I, enlargement of pinnate spiniform seta. Scale bar $=0.1 \mathrm{~mm}$ for $\mathrm{A}-\mathrm{B}$, and $\mathrm{E}$. 
(Fig. 7E). Merus triangular; ventral margin with mid plumose seta and four simple setae on distal half; mid-outer margin with three plumose setae; inner face with bipinnate spiniform seta (Fig. 7F). Carpus about 1.6 time longer than wide, larger than basis, widest distally; ventral margin with ten plumose setae and translucent acute or subacute apophysis; outer margin with row of three sub-proximal plumose setae; sub-distal dorsal margin with translucent acute or subacute apophysis and two simple setae; inner face with sub-distal simple seta on ventral margin (Fig. 7E). Propodus about 1.2 times wider than long; ventral margin with two simple setae; outer margin with five spiniform setae (three ventral and two medial) (Fig. 7C) and two simple setae near articulation of movable finger; dorsal margin with one sub-proximal and one simple seta distally; inner face with simple seta on outer ventral margin; with spiniform seta on mid-medial margin near articulation of movable finger, and "comb row" of five (one biserrate (Fig. 7G) and four inner bipinnate (Fig. 7H)) setae; fixed finger with three ventral setae; one spiniform seta and five sub-marginal simple setae on outer incisive margin, one tooth, with weakly crenulate dorsal margin after tooth and two proximal simple setae of unequal lengths, claw short; inner face with sub-distal, ventro-lateral spiniform seta, margin proximal to tooth with row of four small spines and after tooth with row of seven small spines (Fig. 7E). Dactylus longer than fixed finger, with row of nine (two proximal) spines ventrally (Fig. 7D); inner face with three pinnate spiniform setae on sub-distal margin (Fig. 7I).

Pereopod-1 (Figs 8A-F, 15A-B). Fossorial, strongly developed, with mucus packets on basis, merus, carpus, and propodus (Fig. 15A). Coxa, excluding anterior process, sub-quadrate; distoventral margin with four small simple setae and small denticles adjacent to base of coxal process; distodorsal margin with simple seta and translucent rounded apophysis; inner face with row of ten simple setae (Fig. 8D); coxal process well-developed, triangular, having length about twice width, becoming distally attenuated, terminating in acute tip; ventral margin asetose; dorsal margin with four translucent acute or subacute apophyses and three setulate setae, distal most buttressed and largest. Exopod with three articles, third article bearing six plumose setae. Basis about 2.1 times longer than wide; distoventral margin with two simple setae and spiniform seta; dorsal margin with row of 5-6 translucent acute or subacute apophyses interspersed in row of 7-8 setulate setae, distal most, being smaller, and sub-distal small simple seta; inner face (Fig. 8D) with two small simple setae on ventral margin. Ischium wider than long, with cluster of four simple setae of unequal lengths on distoventral margin (Figs 8A, 15B). Merus about 1.4 times longer than wide, widest distally; ventral margin with three simple setae and sub-distal stout spiniform seta; outer margin with three (one ventral and two dorsal) sub-distal simple setae; distodorsal margin with two inner bipinnate spiniform setae (Fig. 8B); inner face proximal 1/3 with row of four plumose setae (Fig. 8E) and two inner bipinnate spiniform setae extending from mid-face ventrally to dorsal margin, distal half with a row of four setulate setae, and sub-distal row of inner bipinnate spiniform setae. Carpus about 1.2 times longer than wide; ventral margin with two stout spiniform setae; outer distodorsal margin with three simple setae and stout spiniform seta; inner face with semi-circular row of seven inner bipinnate spiniform setae of unequal lengths extending from mid-face ventrally to dorsal margin; distodorsal margin with semi-circular row of seven inner bipinnate spiniform setae being smaller ventrally. Propodus about 1.2 times longer than wide, widest distally; ventral margin with three stout spiniform setae and three simple setae; outer ventral margin with two (one mid and one distal) spiniform setae; dorsal margin with mid plumose seta, one mid simple seta, two (one mid and one sub-distal) bipinnate spiniform setae, and two (subdistal and distal) stout spiniform setae; inner face with one long simple seta and one setulate spiniform seta on distal margin (Fig. 8F). Dactylus together with unguis shorter than propodus, dactylus longer than unguis; ventral margin of dactylus with mid spine with acute tip and small distal divide denticle having two small fine setae (Fig. 8C).

Pereopod-2 (Figs 9A-C, 15C). Longer and less robust than pereopod-1, with mucus packets in basis, merus, carpus, and propodus (Fig. 15C). Coxa with plumose seta and translucent acute or subacute apophysis on distoventral margin. Basis about 3.5 times longer than wide; ventral margin with eight simple setae and sub-proximal plumose seta; outer dorsal margin with two PPS; dorsal margin with two curved translucent acute or subacute apophyses and five small simple setae. Ischium wider than long, with four simple stiff setae of unequal lengths on distoventral margin. Merus about 1.4 times longer than wide, widest distally; ventral margin with six simple setae and three stout spiniform setae (one in the middle and two sub-distal); outer ventral margin with simple seta; distodorsal margin with long setulate seta reaching articulation of the carpus and propodus and simple seta. Carpus about 1.5 times longer than wide; ventral margin with four simple setae and three stout spiniform setae (one in the middle and two sub-distal); outer sub-distal margin with row of three simple setae of unequal lengths; outer and inner margin with a crown of six (two of them extending distally over $3 / 4$ length of propodus) inner bipinnate spiniform seta of varying lengths. Propodus about 4.3 times longer than wide, length about equal to combined lengths of merus and carpus; 
ventral margin with four mid-bipinnate spiniform setae (largest distally) (Fig. 9B), and two simple setae; outer margin with two (sub-ventral and sub-dorsal) simple setae; dorsal margin with sub-distal PSS and simple seta; inner margin with sub-distal bipinnate seta. Dactylus curved, styliform, acutely tip, together with unguis shorter than propodus, dactylus longer than unguis; dactylus with two (middle and distal) small simple setae on ventral margin (Fig. 9C).

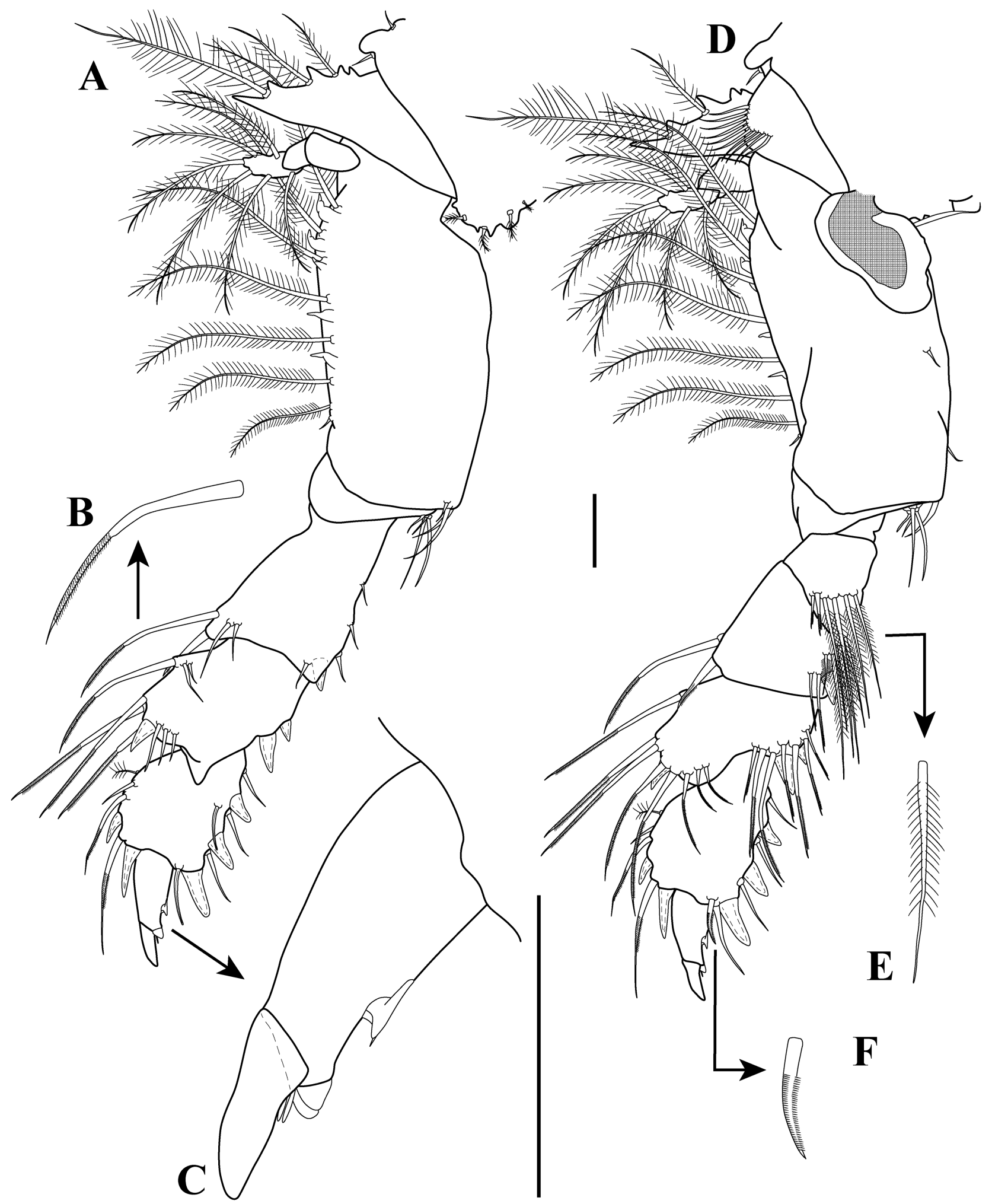

FIGURE 8. Julmarichardia magdae sp. nov. paratype non-ovigerous female. A, pereopod-1, outer view; B, enlargement of inner bipinnate spiniform seta; $\mathrm{C}$, enlargement of dactylus and unguis; D, pereopod-1, inner view; E, enlargement of plumose seta; F, enlargement of setulate spiniform seta. Scale bar $=0.1 \mathrm{~mm}$ for A, C, and D. 


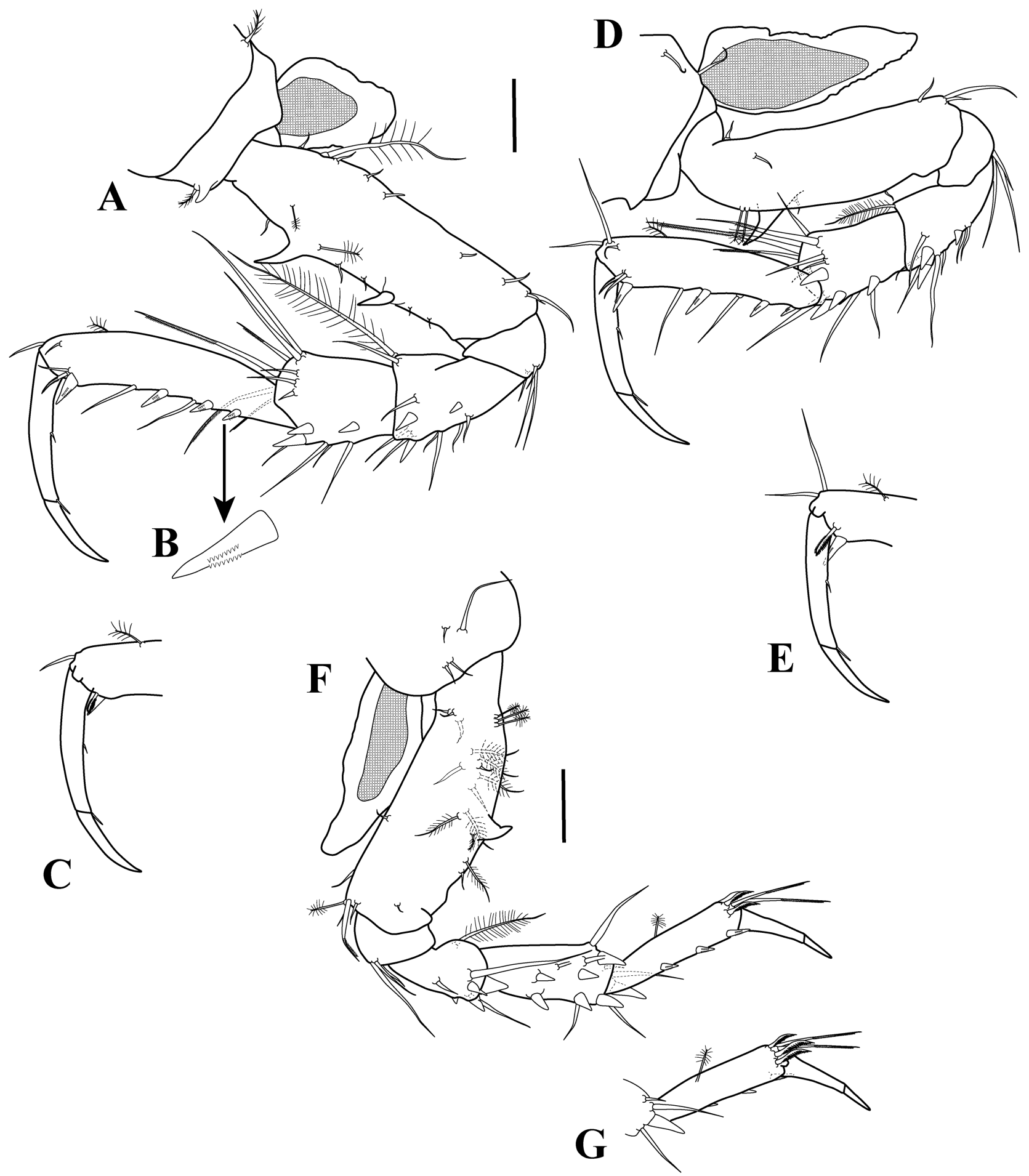

FIGURE 9. Julmarichardia magdae sp. nov. paratype non-ovigerous female. A, pereopod-2, outer view; B, enlargement of mid-bipinnate spiniform setae; C, pereopod-2, propodus, dacylus, and unguis of pereopod-2, inner view; D, pereopod-3, outer view; E, carpus, propodus, dactylus, and unguis of pereopod-3, inner view. F, pereopod-4, outer view; G, carpus, propodus, dactylus, and unguis of pereopod-4, inner view. Scale bar $=0.1 \mathrm{~mm}$ except for B.

Pereopod-3 (Figs 9D-E, 15D). Similar to pereopod-2, but shorter, with mucus packets in basis to propodus (Fig. 15D). Basis with ventral margin lacking proximal setulate and fewer small simple setae; dorsal margin with proximally curved translucent acute or subacute apophysis. Merus with distodorsal margin having shorter setulate seta, not extending to articulation of the carpus and propodus. Propodus with two distodorsal simple setae (Fig. 9E). 
Pereopod-4 (Figs 9F-G, 15E). Shorter than other pereopods, with mucus packets in basis to propodus (Fig. 14E). Coxa with four simple setae of unequal lengths on mid-outer margin. Basis about 2.8 times longer than wide; ventral margin with four (one in the middle, one sub-distal, and two distal) simple setae, with plumose seta and inner bipinnate spiniform seta distally; outer margin with two setulate setae and six simple setae; dorsal margin with three proximal plumose setae, with four small simple setae, and mid-curved translucent acute or subacute apophysis. Ischium wider than long, with three simple stiff setae of unequal lengths on distoventral margin. Merus about 1.3 times longer than wide; ventral margin with four (three sub-distal and one distal (most stout) spiniform setae, and three (middle and two sub-distal) simple setae; distodorsal margin having shorter setulate seta, not extending to articulation of the carpus and propodus. Carpus about 2.3 times longer than wide; ventral margin with three stout spiniform setae and simple setae; outer margin with two stout spiniform seta and two simple setae; sub-distal dorsal margin with simple seta and stout spiniform seta; inner distal margin with three simple setae and stout spiniform seta (Fig. 9G). Propodus about 4.3 times longer than wide; ventral margin with three mid-bipinnate spiniform setae, largest distally; dorsal margin with mid plumose seta, and four (two pectinate and two inner bipinnate) spiniform setae; inner sub-distal margin with three pectinate spiniform setae (Fig. 9G). Dactylus curved, together with unguis shorter than propodus, dactylus longer than unguis.

Pereopod-5 (Figs 10A-B, 15F). Coxa with distoventral simple seta, with mucus packets in basis, merus, carpus, and propodus (Fig. 15F); outer margin with two long setulate setae; dorsodistal margin with simple seta. Basis about 2.7 times longer than wide; ventral margin with seven setulate setae of unequal lengths and two simple setae; outer margin with a row of eight long plumose setae being smaller distally; dorsal margin with proximal plumose seta and three small simple setae; inner dorsal margin with two simple setae. Ischium wider than long, with plumose seta and two simple setae on distoventral margin. Merus about 1.9 times longer than wide; ventral margin with four plumose setae and sub-distal stout spiniform seta; outer margin with four (two simple and two setulate) and sub-distal stout spiniform seta; mid-dorsal margin with three very long (extending distally over half length of propodus) plumose setae. Carpus about 1.8 times longer than wide; ventral margin with three stout spiniform setae and simple seta; outer margin with a row of two stout spiniform setae, simple and plumose seta; dorsal margin with two (middle and sub-distal) very long plumose setae; inner margin with three (one long and two small) simple setae. Propodus about 4.1 times longer than wide; ventral margin with three mid-bipinnate spiniform setae, largest distally; sub-distal dorsal margin with simple seta and inner bipinnate seta; inner sub-distal ventral margin with three small spiniform setae and inner sub-distal dorsal margin with plumose seta and simple seta (Fig. 10B). Dactylus curved, together with unguis shorter than propodus, dactylus longer than unguis, shallow apophysis ventrally at articulation with propodus; dactylus with two mid-dorsal simple setae; with distal simple seta on ventral margin.

Pereopod-6 (Figs 10C-E, 15G). Similar to pereopod-5 but slightly longer, with mucus packets in basis to propodus (Fig. 15G). Basis with ten plumose long setae on ventral margin; outer margin with a row of seven plumose setae and three PSS proximally; dorsal margin with translucent acute or subacute apophysis and eight plumose setae. Merus with six plumose setae on ventral margin; outer margin with four plumose setae; mid-dorsal margin with four very long (three extending distally over half length of propodus and one extending distally over proximal length of dactylus) plumose setae; inner sub-distal ventral margin with plumose seta. Carpus with four plumose setae on ventral margin; outer margin with three plumose setae; mid-dorsal margin with three (two middle and one sub-distal) very long plumose setae. Propodus with three slender spiniform setae on ventral margin; outer margin with sub-distal simple seta; dorsal margin with inner bipinnate seta; inner sub-distal margin with simple seta and mid-distal plumose seta; distally with oblique semi-circle of $\sim 25$ (Fig. 10D, $\sim$ five of them on outer view (Fig. 10C)) setulate spiniform, lanceolate setae (Fig. 10E).

Pleopods (Fig. 11A-C). Five well-developed, biramous pairs. Pleopod-1 (Fig. 11A): basal article, 1.4 times longer than wide, shorter than both rami, inner margin with two plumose, setae; exopod shorter than endopod, with 19 plumose setae. Endopod with 19 plumose setae (one seta with whiplike tip (Fig. 11B)). Pleopods 2-5 (Fig. 11C) similar to pleopod-1 but becoming progressively smaller posteriorly and number of plumose setae on both rami decreases.

Uropod (Fig. 11D-E). Biramous. Basal article 2.7 times longer than wide, widest distally forming shallow inner distal lobe; sub-distal and distal margin with several plumose setae on dorsal (Fig. 11D) and ventral view (Fig. 11E). Exopod of three apparent articles or pseudo-articles; article-1 inner margin with mid simple seta; article-2 shorter, asetose; article-3 longest, with three long simple setae of varying lengths. Endopod of 15 articles or pseudo-articles; articles 2, 5, 9, and 13 with 2-3 plumose setae and 1-3 simple setae; articles 1, 3-4, 6-8, 10, 12, and 14 asetose; article-11 with distal simple seta; terminal article with plumose seta and three setae of unequal lengths distally. 

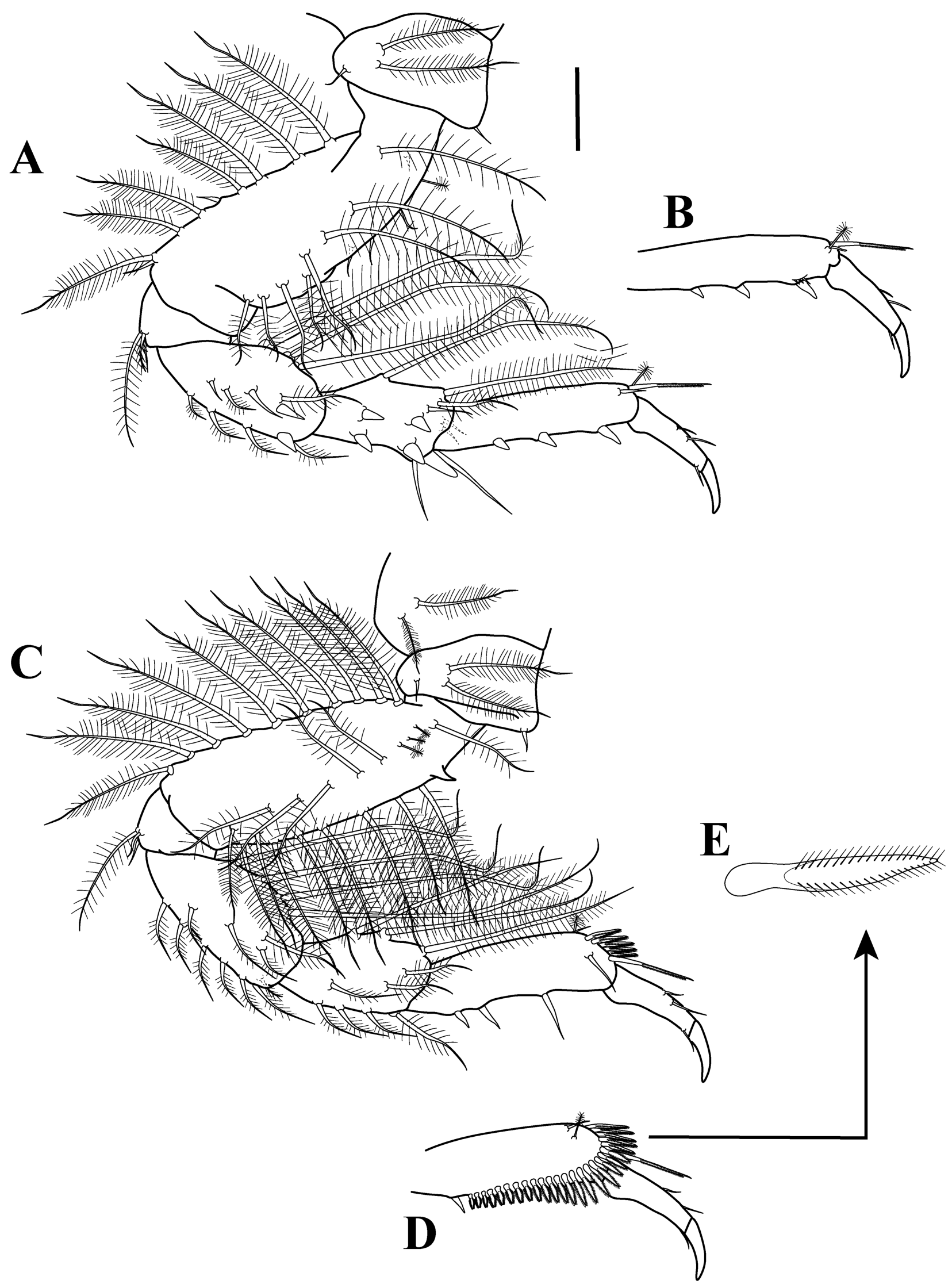

FIGURE 10. Julmarichardia magdae sp. nov. paratype non-ovigerous female. A, pereopod-5, outer view; B, propodus, dactylus, and unguis of pereopod-5, inner view; C, pereopod-6, outer view; D, propodus, dactylus, and unguis of pereopod-6, inner view; E, enlargement of setulate spiniform, lanceolate setae. Scale bar $=0.1 \mathrm{~mm}$ except for $\mathrm{E}$. 

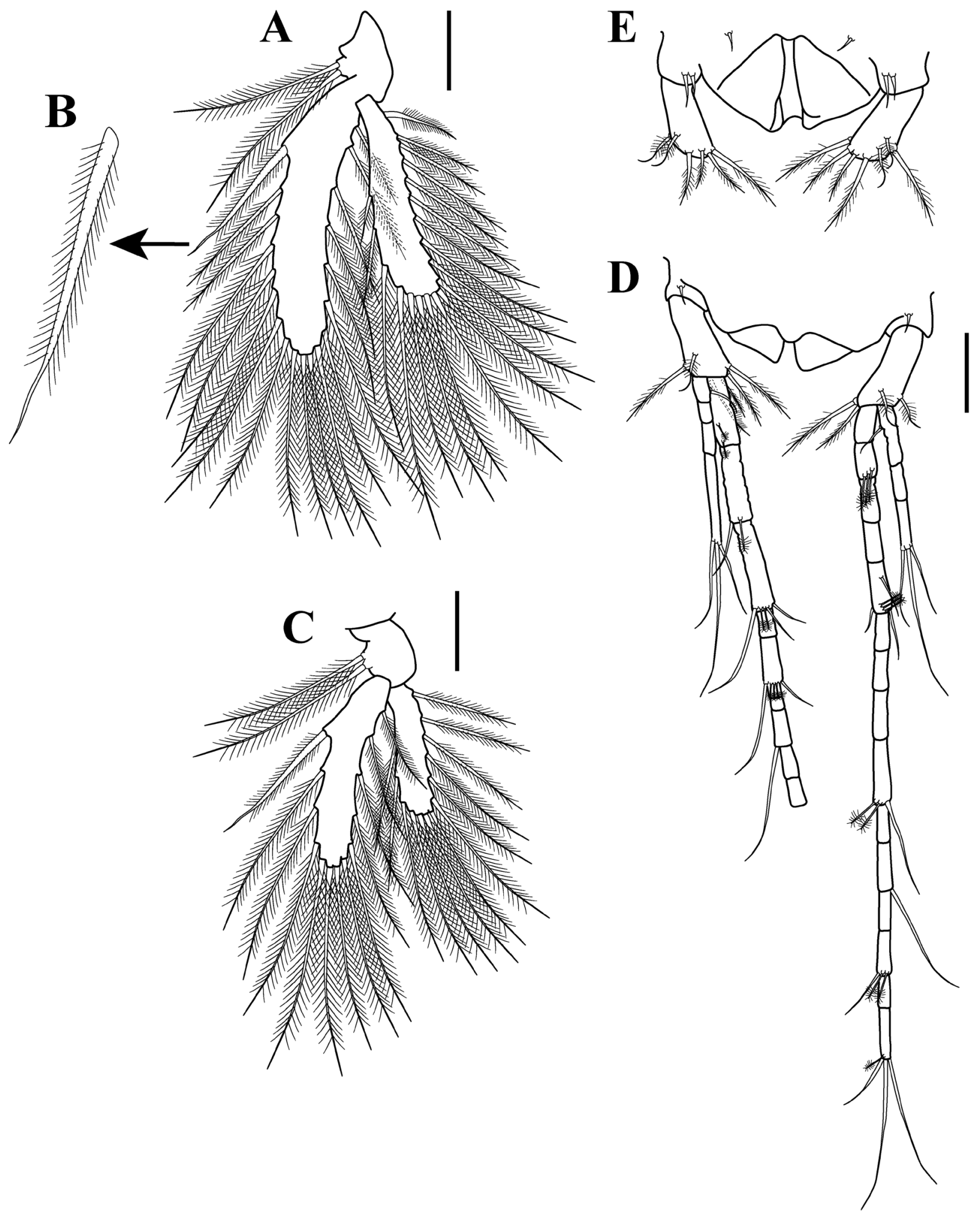

FIGURE 11. Julmarichardia magdae sp. nov. paratype non-ovigerous female. A, pleopod-1; B, enlargement of plumose setae with whiplike tip; C, pleopod-5; D, uropod, dorsal view; E, uropodal basal article, ventral view. Scale bars $=0.1 \mathrm{~mm}$ except for B.

Ovigerous female. Similar to non-ovigerous females. Carrying more than $\sim 19$ eggs.

Body (Fig. 18B). Length $3.8 \mathrm{~mm}$.

Adult male. Overall similar to adult females, except in having rostrum with rounded tip but slightly more acute, size of the chelipeds, pereonites 2-5 with hyposphenia, and hyposphenia present in on all pleonites.

Body (Fig. 19A-B). Length $2.7 \mathrm{~mm}$. 
Cheliped (Figs 12A-B, 17A). Robust, with mucus packets in carpus to dactylus (Fig. 17A). Exopod with three articles, third article bearing four plumose setae. Basis about 1.4 times longer than wide; ventral margin with stout spiniform seta on mid-margin, and three sub-distal plumose setae; inner face with four (one proximal and three on the middle) small simple setae on dorsal margin (Fig. 12B). Merus triangular; ventral margin with plumose seta and simple seta on proximal half, with plumose seta on distal half, and two translucent acute or subacute apophyses subdistally; mid-outer margin with two plumose setae; inner face with mid-outer margin with bipinnate spiniform seta (Fig. 12B). Carpus about 1.1 times longer than wide, larger than basis, widest distally; mid ventral margin with two plumose setae, simple seta, and four translucent acute or subacute apophyses, distal with simple seta at base; dorsal margin with a row of five plumose setae, three small simple setae, and mid translucent acute or subacute apophyses with simple seta at base distally; inner face with mid plumose seta after translucent acute or subacute apophysis on ventral margin (Fig. 12B). Propodus massive; about 1.1 times wider than long; outer margin with three spiniform setae (two ventral and one medial) and three simple setae near articulation of movable finger; dorsal margin with simple seta distally; inner face with simple seta on ventral margin, with "comb row" of five (one biserrate and four inner bipinnate) spiniform setae on mid-medial margin near articulation of movable finger (Fig. 12B); fixed finger with five ventral setae; with three spiniform seta and three sub-marginal simple setae on outer incisive margin, with tooth, with two spiniform setae before and after of base of tooth, and with simple seta at mid-anterior margin of tooth, claw short; inner margin with three (ventral, medial, and sub-distal) simple setae ventro-lateral margin; medial margin with four spiniform seta; dorsal edge with two spiniform setae before and after of base of tooth (Fig. 12B). Dactylus longer than fixed finger, with row of eight spines ventrally; inner face with two spiniform setae on sub-distal margin (Fig. 12B).

Pereopod-1 (Figs 13A-B, 17B). Similar to female, but shorter and the translucent acute or subacute apophysis are bigger and stronger. Dorsal margin of coxal process with two setulate setae. Exopod not shown.

Mucus glands/storage sites (Figs 14-17). Occurring on antennular article-1 (Fig. 14A); antennal article-2 (Fig. 14B); within carpus to dactylus of female cheliped (Fig. 14C) and within carpus to propodus of male cheliped (Fig. 17A); within basis to propodus of pereopods 1-6 in female (Fig. 15) and male (Fig. 17B); and in pleotelson in dorsal and ventral view (Fig. 16).

Intraspecific variation. Julmarichardia magdae sp. nov. exhibits some degree of variation between left and right side of the same specimen, and among the individuals examined during this study as follows:

(1) Number of articles on the antennular outer and inner flagellum observed on a non-ovigerous, ovigerous females, and males varied from 7-8 and 3-4, respectively.

(2) Number of articles on the uropodal exopod and endopod of a non-ovigerous, ovigerous females, and males varied from 3-4 and 12-15, respectively.

(3) Number of translucent acute or subacute apophysis on basis of pereopod-1 of a non-ovigerous, ovigerous females, and males varied from 5-6.

(4) Number of spiniform setae on the ventral margin of propodus of pereopods 2-3 of a non-ovigerous, ovigerous females, and males varied from 3-4. This number can vary between right and left side of the same specimen.

(5) Number of translucent acute or subacute apophysis occurring in the proximal basis of the pereopod-2 varied from 1-2 (only observed in the left side of an ovigerous female).

(6) Number of translucent acute or subacute apophysis occurring in the proximal basis of the pereopod-4 varied from 1-2 (only observed in both sides of an ovigerous female).

(7) Overall, males having robust symmetrical chelipeds were found most of the time; however, two males were observed having one of the chelipeds (e.g. right for one and left for another) small and thin similar to the female cheliped.

Size-distribution. The non-ovigerous females (females with oostegites) ranged from 1.8 to $3.4 \mathrm{~mm}(\mathrm{n}=13$ ) (Fig. 18A). Ovigerous females varied from 2.4 to $3.6 \mathrm{~mm}(\mathrm{n}=12)$ (Fig. 18B). Adult males ranged from 2.4 to 2.8 $\mathrm{mm}(\mathrm{n}=13)$ (Fig. 19).

Remarks. Based on the dentate basal article of the antenna and the anterior margin of the basis of pereopod-1 having distinct blunt spiniform processes, the new Australian species is referrable to the genus Julmarichardia. It represents the second species described from Australian waters, the first being $J$. gutui, which was collected from the same general area as part of the same baseline study but in shallow waters depths, usually between $41-43 \mathrm{~m}$. 

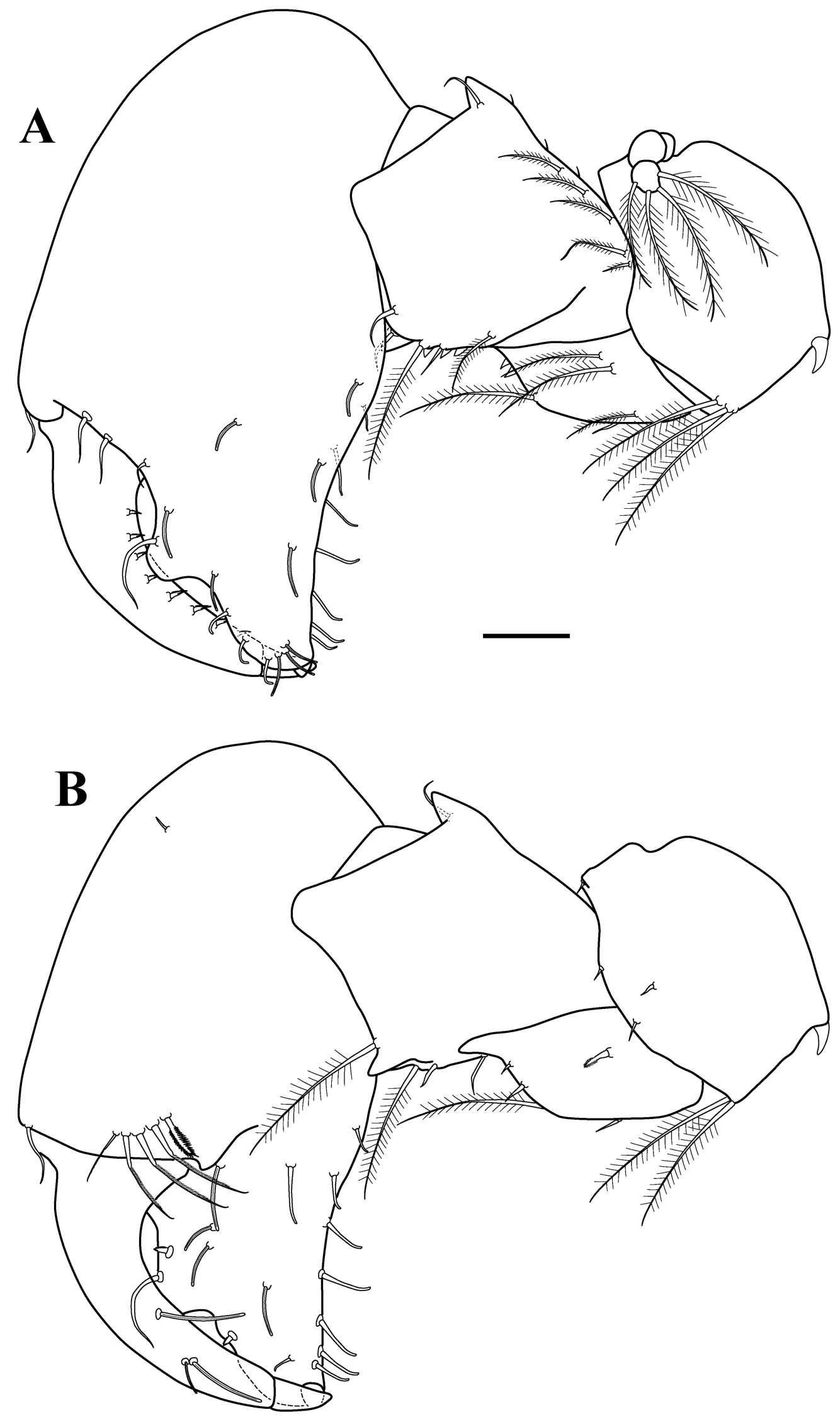

FIGURE 12. Julmarichardia magdae sp. nov. paratype male. A, cheliped, outer view; B, cheliped, inner view. Scale bar $=0.1$ $\mathrm{mm}$. 

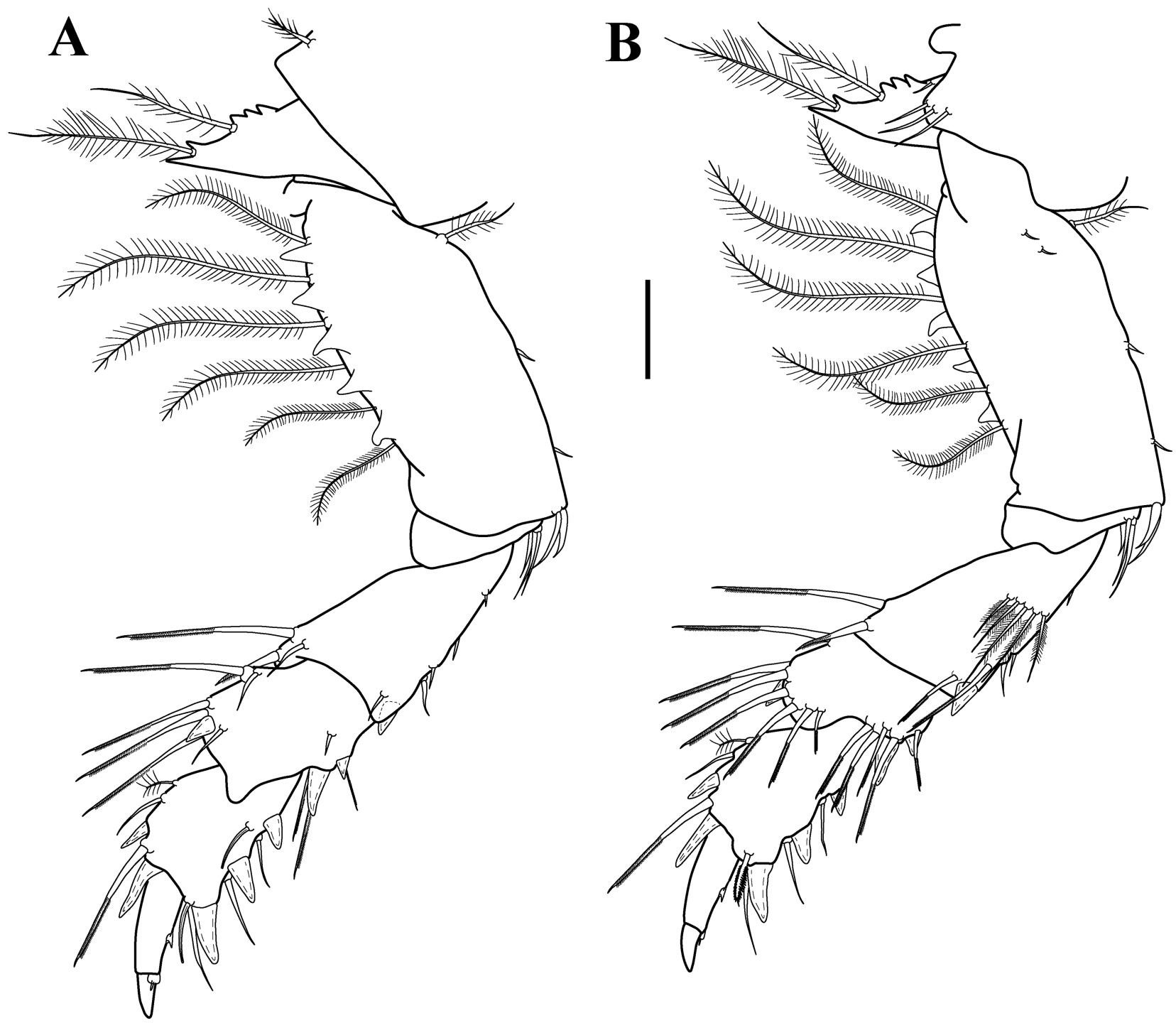

FIGURE 13. Julmarichardia magdae sp. nov. paratype male. A, pereopod-1, outer view; B, pereopod-1, inner view. Scale bar $=0.1 \mathrm{~mm}$.

Julmarichardia magdae is distinguished from $J$. gutui and other members of its genus by (1) left lacinia mobilis with six denticles, and (2) pereopod-1 coxal process acute, well-developed, with four translucent acute or subacute apophyses and 2-3 plumose setae on dorsal margin. The new Australian species specifically differs from $J$. thomassini by having (1) a spatulate rostrum (triangular terminating in acute tip in $J$. alinati and sub-triangular ending in rounded tip in $J$. thomassini), (2) mandible palp article-1 with inner margin bearing eight setulose spiniform setae (four simple setae in both, J. alinati and $J$. thomassini), (3) maxillule palp article-2 having three sub-distal/distal setae (two in J. alinati and six in J. thomassini), (4) maxillipedal basis inner sub-distal margin having three welldeveloped setulate setae (one in both, J. alinati and J. thomassini), (5) pereopod-1 carpus having ventral margin with two (sub-distal and distal) stout spiniform setae (just one in J. alinati), (6) pereopod-2 basis having dorsal margin with two curved translucent acute or subacute apophyses (one in $J$. thomassini), and (7) pereopod-3 propodus having ventral margin bearing four mid-bipinnate spiniform setae (three in J. alinati). Julmarichardia magdae can be separated from J. deltoides by (1) a spatulate rostrum (triangular ending in an acute tip in J. deltoides) and (2) antennule with article-1 having acute short mid-marginal translucent acute apophyses (four to six in J. deltoides). Julmarichardia magdae can be distinguished from the other species of the genus in the illustrated dichotomous identification key (see below). 

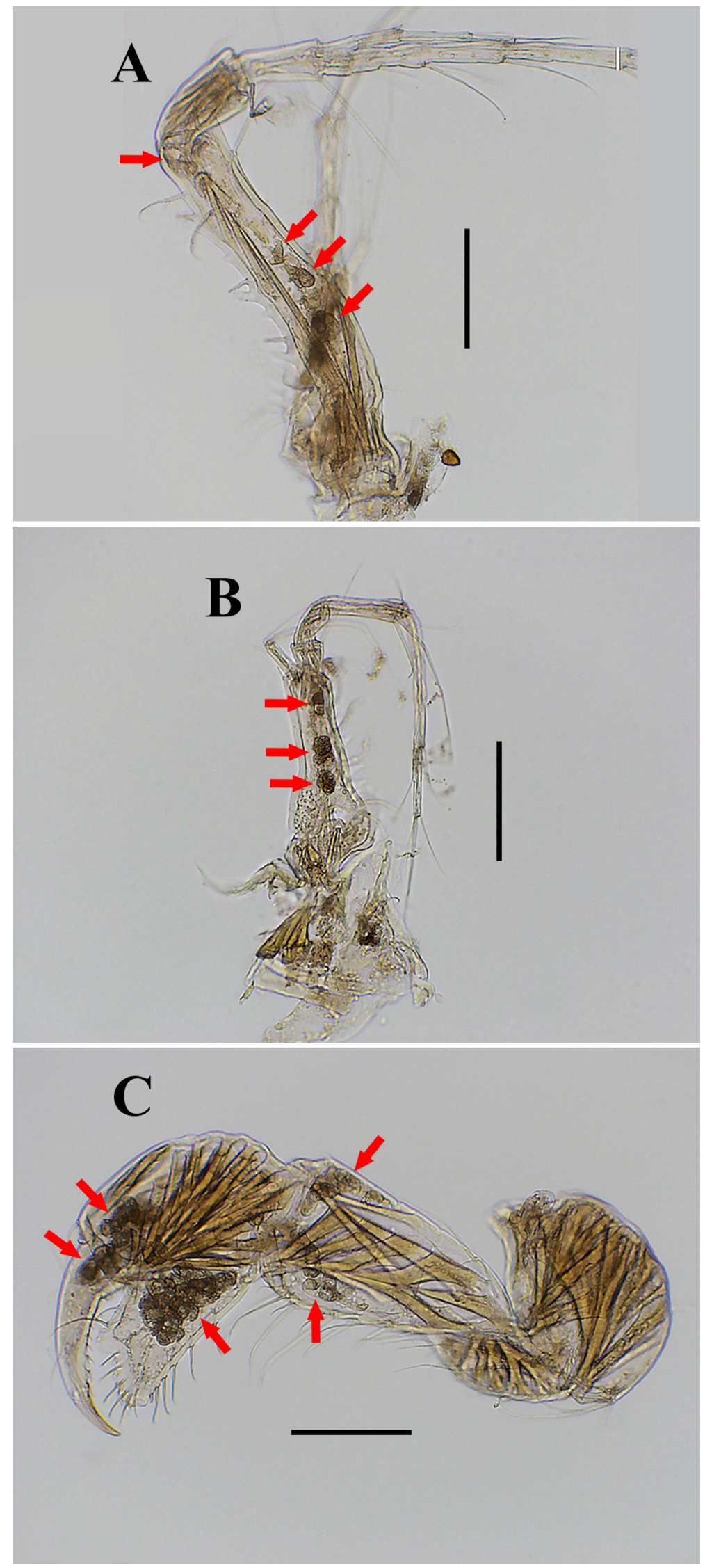

FIGURE 14. Digital images of Julmarichardia magdae sp. nov. paratype non-ovigerous female. A, antennule, dorsal view; B, antenna, ventral view; C, cheliped, outer view. Red arrows shown the presence of mucus packets. Scale bars $=0.2 \mathrm{~mm}$. Photos by A.G. Morales-Núñez. 


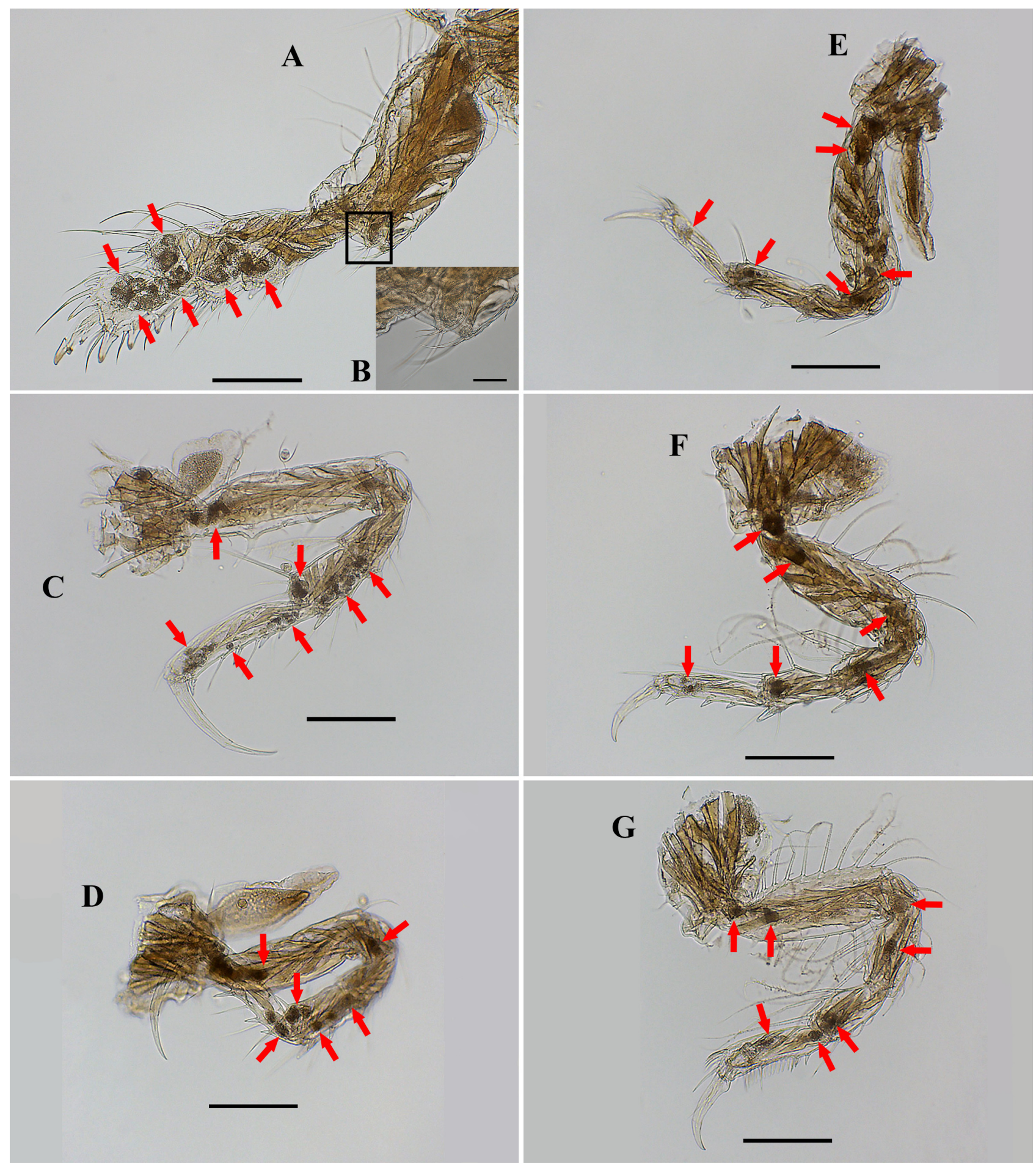

FIGURE 15. Digital images of Julmarichardia magdae sp. nov. paratype non-ovigerous female. A, pereopod-1, inner view; B, enlargement of distoventral margin of ischium, inner view; C, pereopod-2, D, pereopod-3, E, pereopod-4; F, pereopod-5; G, pereopod-6. Red arrows shown the presence of mucus packets. Scale bars $=0.2 \mathrm{~mm}$ for A, C-G, and $0.05 \mathrm{~mm}$ for B. Photos by A.G. Morales-Núñez.

Julmarichardia magdae and $J$. gutui rarely co-occurred at the same site but $J$. magdae generally occurred in depths ranging from 37 to $83 \mathrm{~m}$, whereas $J$. gutui occurred in depths between 52 and $86 \mathrm{~m}$ (Table 1). Currently the two Australian species represent the only sympatric members of the genus. Since our material is limited to the two areas of the Northwest Australian Shelf having depth ranges between 37 and $83 \mathrm{~m}$ and 52 and $86 \mathrm{~m}$, respectively, it is not possible to determine the depth limits for the two-species other than that of $J$. magdae may not exceed $83 \mathrm{~m}$ and that of $J$. gutui is greater than $52 \mathrm{~m}$ in this region. 

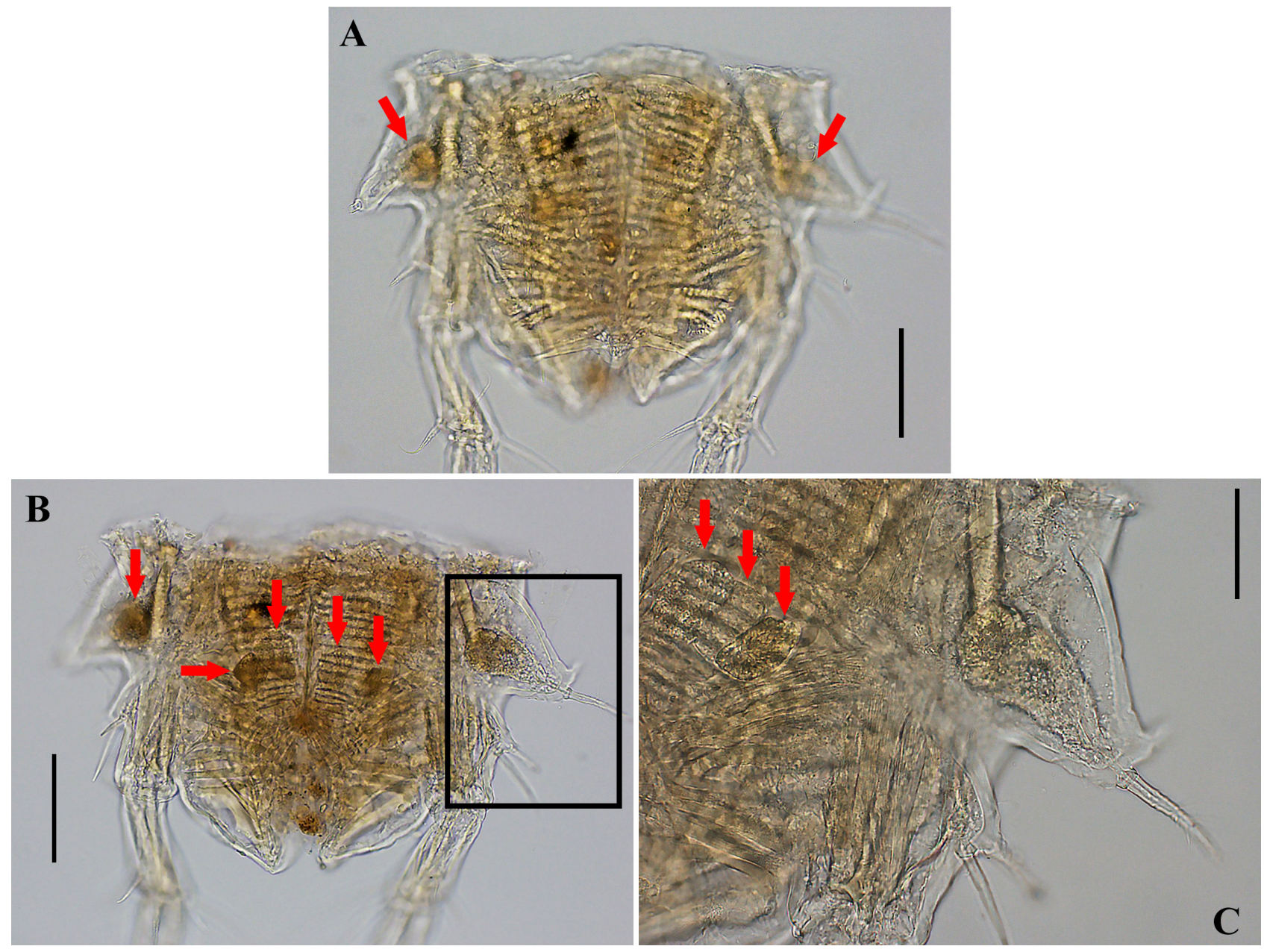

FIGURE 16. Digital images of Julmarichardia magdae sp. nov. paratype non-ovigerous female. A, pleotelson, dorsal view; $\mathrm{B}$, pleotelson, ventral view; C, enlargement of antero-laterally apophysis and mid margin, ventral view. Red arrows shown the presence of mucus packets. Scale bars $=0.2 \mathrm{~mm}$ for A-B and $0.05 \mathrm{~mm}$ for C. Photos by A.G. Morales-Núñez.

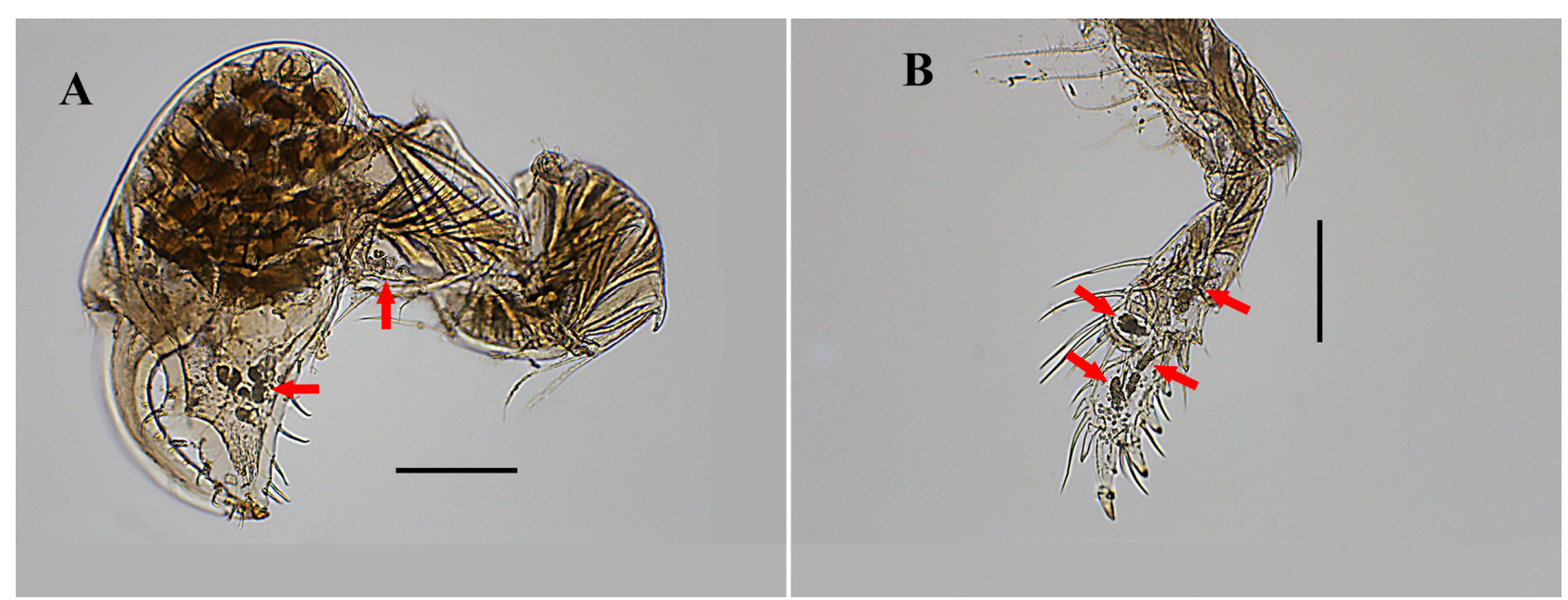

FIGURE 17. Digital images of Julmarichardia magdae sp. nov. paratype male, outer view. A, cheliped, outer view, B, pereopod1, outer view. Red arrows shown the presence of mucus packets. Scale bars $=0.2 \mathrm{~mm}$. Photos by A.G. Morales-Núñez. 


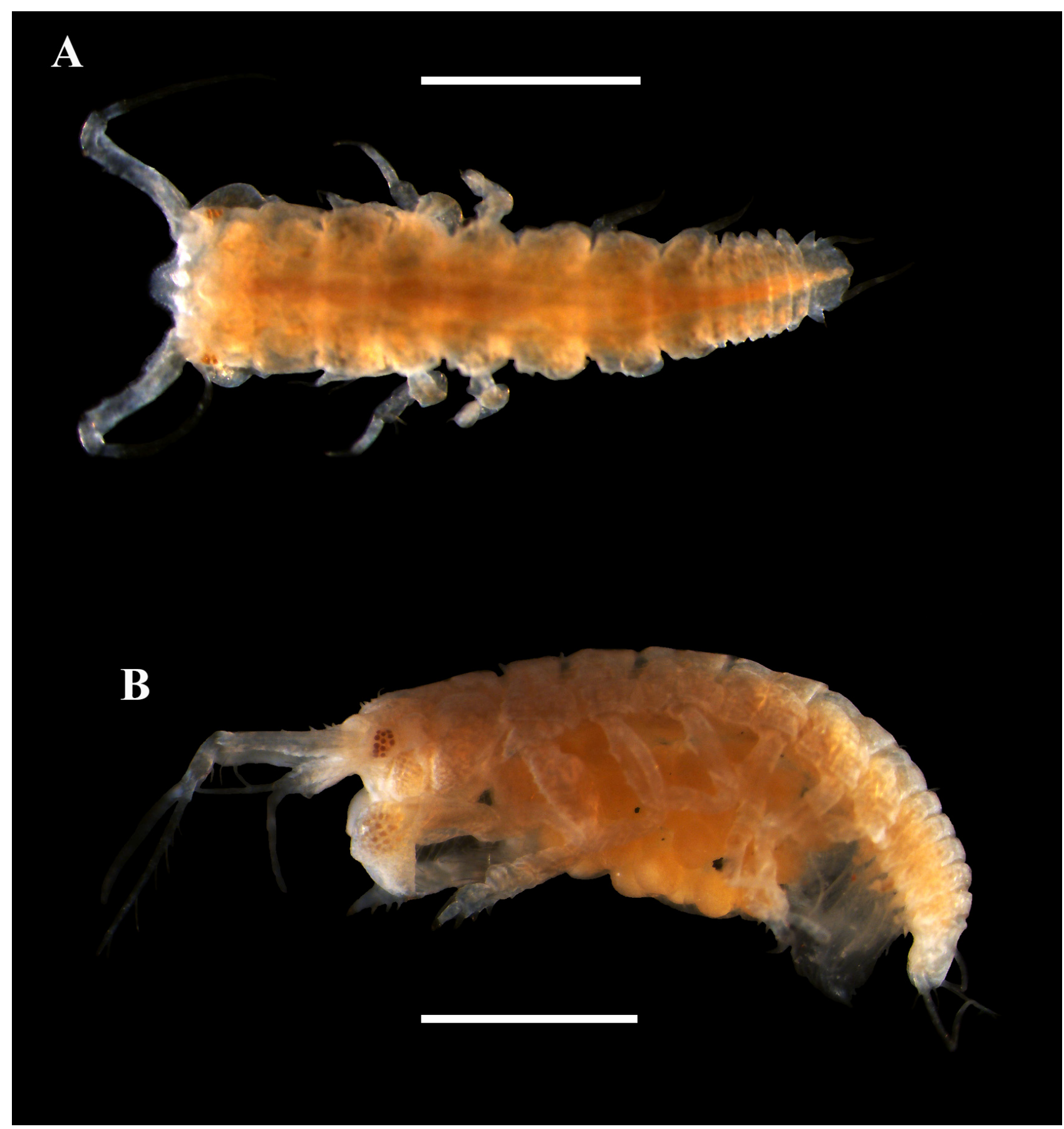

FIGURE 18. Digital images of Julmarichardia magdae sp. nov. A, paratype (non-ovigerous female), dorsal view of habitus, length $3.2 \mathrm{~mm}$; B, paratype (ovigerous female) lateral view of habitus, length $3.8 \mathrm{~mm}$. Scale bar $=1.0 \mathrm{~mm}$. Photos by A.G. Morales-Núñez.

Bamber \& Sheader (2005), and Ritger \& Heard (2007) extended the known range for genus Julmarichardia westward to Malaysia and eastward to Northwest Australia, respectively, to encompass the east-west breadth of the Indian Ocean (Fig. 2). Bathymetric and distribution data for the genus Julmarichardia is presented in Table 1. Based on the limited data available for the six species of Julmarichardia, J. alinati has both the shallowest (6 m) and deepest $(450 \mathrm{~m})$ depth records known for the family. Another species, J. thomassini is known for deep water (250 $\mathrm{m})$, while the four remaining Indo-Pacific species are known from the inner Continental Shelf from depths ranging from 37 to $90 \mathrm{~m}$. 


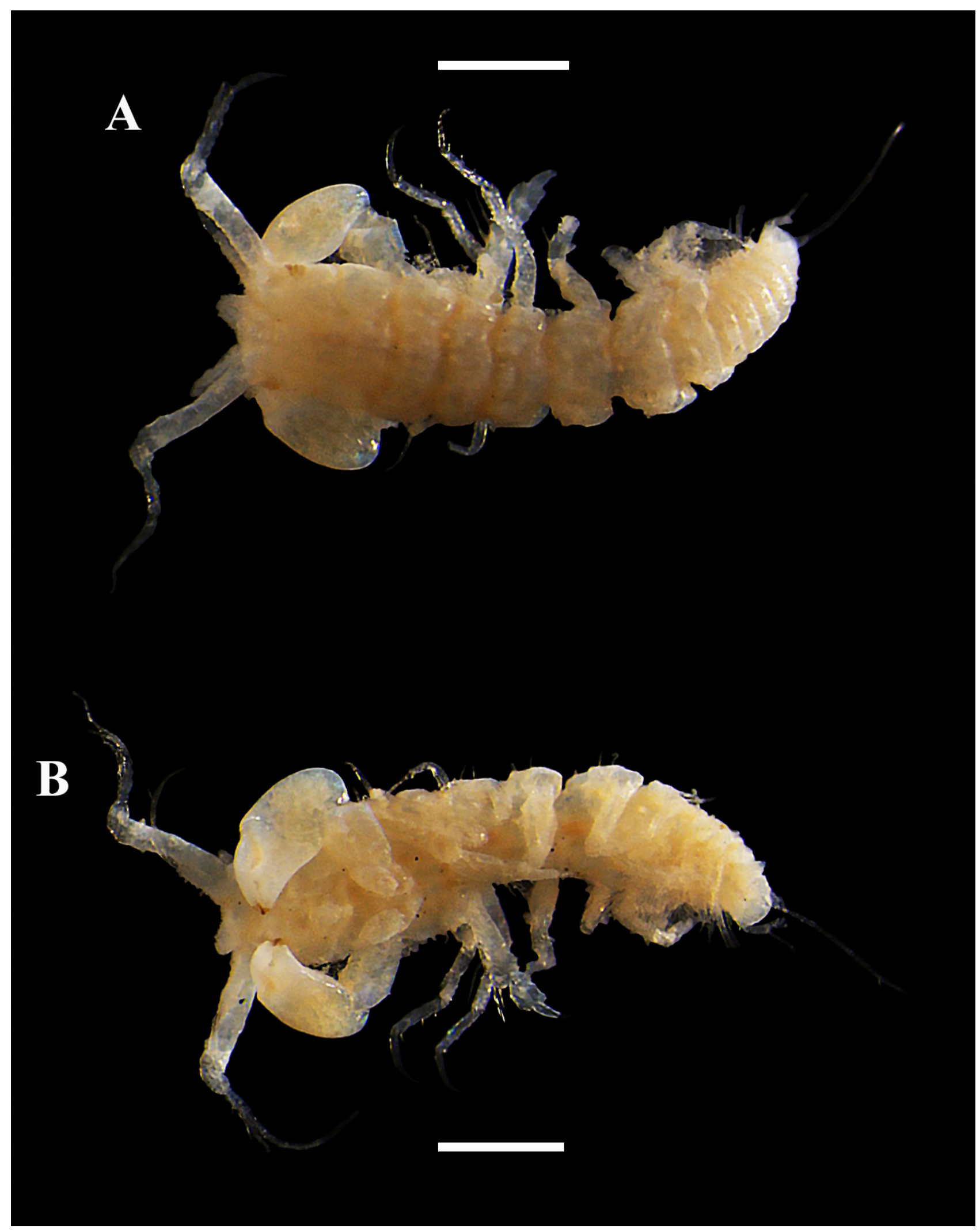

FIGURE 19. Digital images of Julmarichardia magdae sp. nov. paratype male. A, dorsal view of habitus, length $2.7 \mathrm{~mm}$; B, ventral view of habitus. Scale bar $=1.0 \mathrm{~mm}$. Photos by A.G. Morales-Núñez. 

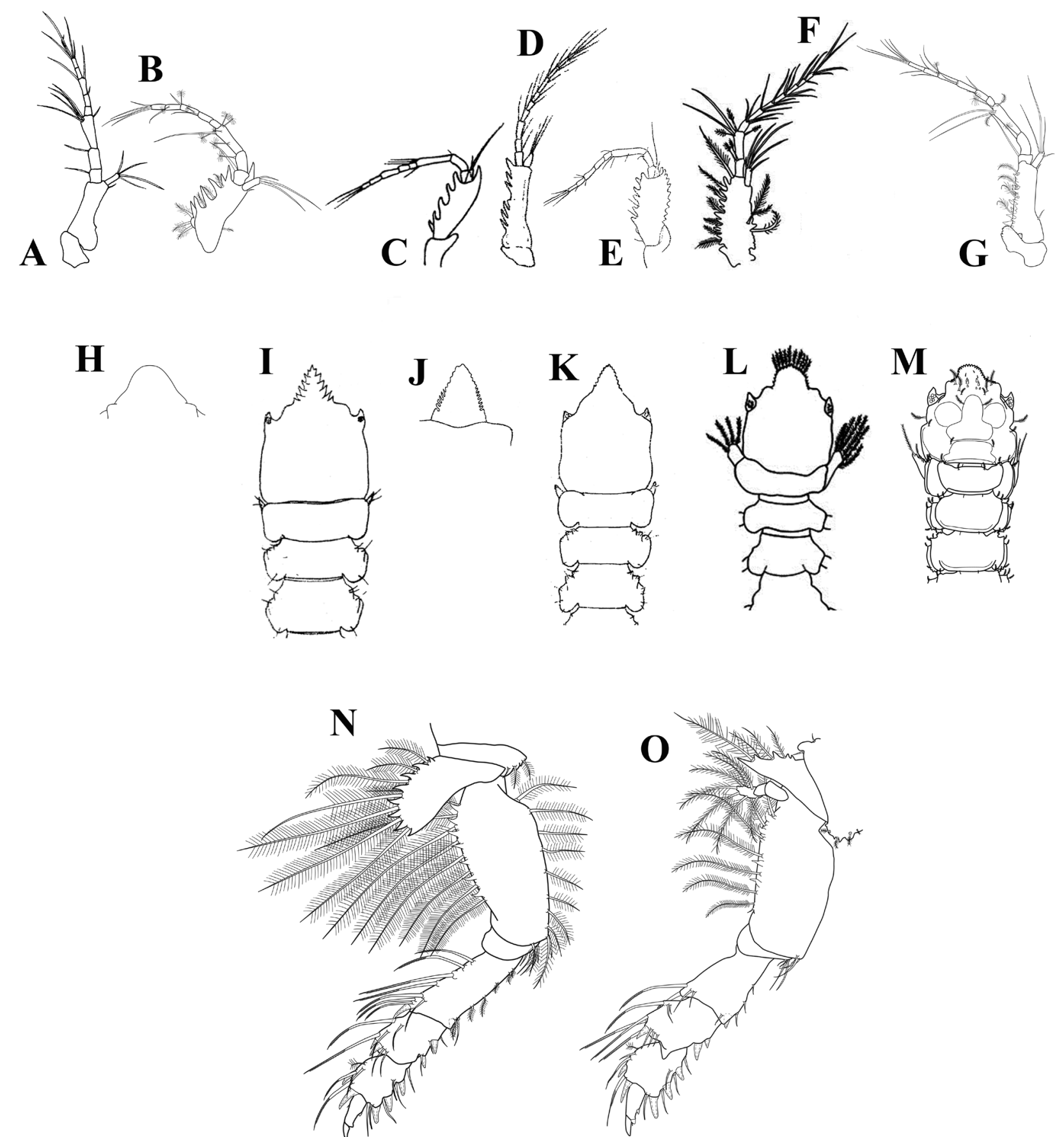

FIGURE 20. Antenna: A, Richardjulmaia bajau; B, Julmarichardia sp. A; C, J. alinati; D, J. deltoides; E, J. thomassini: F, J. gutui; G, J. magdae sp. nov. Rostrum: H, J. sp. A; I, J. alinati; J, J. deltoides; K, J. thomassini: L, J. gutui; M, J. magdae sp. nov. Pereopod-1: N, J. gutui; O, J. magdae sp. nov. [Figures modified from: A, Bamber \& Sheader (2005); B, G-H, M-O, Morales \& Heard (this study); C, E, I, K, Guţu (1989a); D, J, Barnard (1914); F, L, Ritger \& Heard (2007)]. Not to scale. 
We have reexamined type material and topotypical material of $J$. gutui, made corrections and additions to the morphology of its chelipeds and pereopods 1,2 and 3 and observations on the species size distribution and interspecific variation, which are presented below.

Diagnosis. See Ritger \& Heard (2007).

Amended diagnosis. Presence of mucus packets on several parts of body.

Material examined.-Paratypes: two $\hat{\partial} \hat{\partial}$, two $\circ \propto$ (GCRL 2069). - Other topotypical material. —one SA,

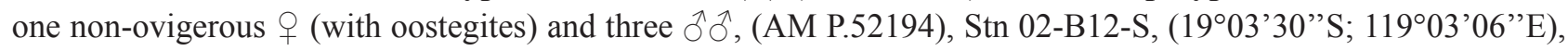
depth 82 m, Coll: FRV "Soela", CSIRO 28-Apr-1983.- two non-ovigerous + (with oostegites) and one ${ }^{\lambda}$, (AM P.52211), Stn 06-B12-S, (1903'00”S; 11902'23”E), depth 80 m, Coll: FRV “Soela”, CSIRO 12-Dec-1982.—one non-ovigerous + (with oostegites), (AM P.105701), Stn 04-B16-S, (2001'12”S; 116 57’36”'E), depth 52 m, Coll: FRV "Soela", CSIRO 04-Sep-1983. - three SA, seven non-ovigerous 우 (with oostegites) (two broken), one $ᄋ$

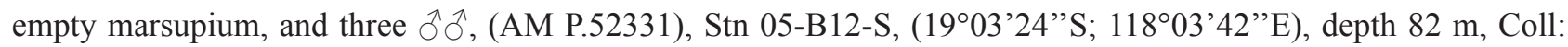
FRV "Soela", CSIRO 23-Oct-1983. - five SA, six non-ovigerous 우우 (with oostegites) (one damaged), two 우우 with empty marsupium (one broken), and three ${ }^{\lambda}{ }^{\lambda}$ (one damaged), (AM P.52335), Stn 05-B10-S, (1904'54"S; $118^{\circ} 52^{\prime} 12$ ”E), depth 82 m, Coll: FRV “Soela”, CSIRO 23-Oct-1983.- two SA, three non-ovigerous 우 (with oostegites), one ovigerous + , one $q$ empty marsupium, four $\hat{\alpha} \hat{\alpha}$, and three undetermined, (AM P.52336), Stn 05-B11S, (1904'06"S; 11900'48”E), depth 82 m, Coll: FRV “Soela", CSIRO 23-Oct-1983.- two SA, two non-ovigerous 우 (with oostegites), and one ovigerous 우, (AM P.52341), Stn 01-B2-S, (1908'24”'S; 11902'24”'E), depth 78 m, Coll: FRV "Soela", CSIRO 11-Dec-1982.-four SA, two non-ovigerous ${ }_{+}$(with oostegites), one ovigerous + ,

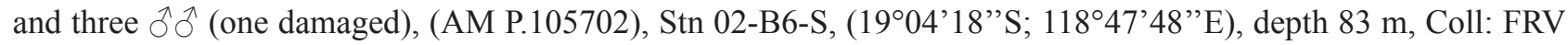
"Soela", CSIRO 27-Apr-1983.- one SA, three non-ovigerous 우우 (with oostegites), two ovigerous 우우, eight $\delta^{\Uparrow}{ }^{\lambda}$, and two undetermined, (AM P.52354), Stn 01-B6-S, (1904'24"S; 118 47'30"E), depth 82 m, Coll: FRV "Soela",

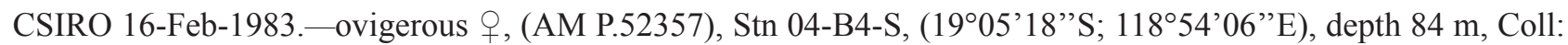
FRV "Soela", CSIRO 29-Aug-1983.--three SA, 11 non-ovigerous 우우, 31 non-ovigerous $ㅇ$ (with oostegites)

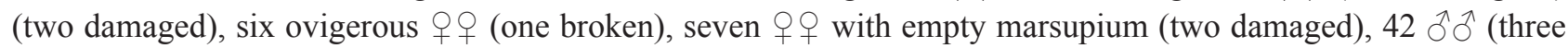
damaged), and six undetermined (one broken), (AM P.52364), Stn 04-B12-S, (1903'24”S; 11903'18”'E), depth 81 m, Coll: FRV "Soela", CSIRO 01-Sep-1983.- one SA and two non-ovigerous $q$, and one ovigerous $q$ (with oostegites), (AM P.52368), Stn 03-B12-S, (1903'00"S; 11904'06”'E), depth 82 m, Coll: FRV "Soela", CSIRO 30-Jun-1983.- - seven non-ovigerous $q+q$ (with oostegites), three ovigerous $q+q$, one $q$ with empty marsupium, five

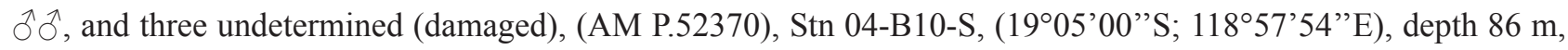
Coll: FRV "Soela", CSIRO 29-Aug-1983.-four non-ovigerous 우우 (with oostegites), two ovigerous $q$ 우, one $q$ with empty marsupium, six ô ô, (AM P.52372), Stn 01-B4-S, (1905'18"'S; $118^{\circ} 54^{\prime} 00^{\prime \prime}$ ), depth 82 m, Coll: FRV "Soela", CSIRO 15-Feb-1983.-11 SA (on with right chela smaller and two with left chela smaller), One $O$ with oostegites (partially dissected), TBL $4.9 \mathrm{~mm}, \mathrm{XXXX}, 11$ non-ovigerous $q+q$ (with oostegites), two ovigerous $q$ 우,

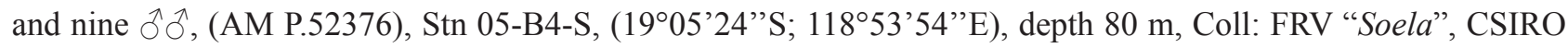
30-Oct-1983. - two non-ovigerous $q+{ }^{2}$ (with oostegites), two ovigerous $q+q$, one $q$ with empty marsupium, one

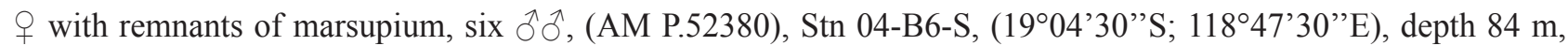
Coll: FRV "Soela", CSIRO 28-Aug-1983.- - eight SA, 13 non-ovigerous $ㅇ+($ (with oostegites), four ovigerous $q$ 우

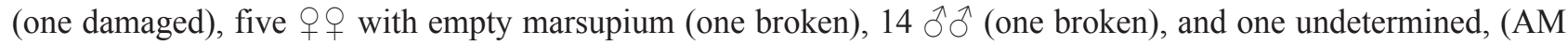
P.52388), Stn 05-B6-S, (1904'05”S; 118 47'47”E), depth 82 m, Coll: FRV “Soela”, CSIRO 30-Oct-1983.-13

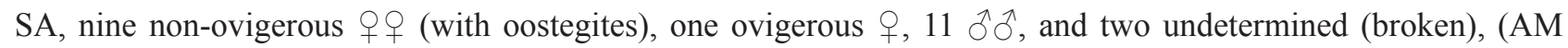
P.105703), Stn 01-B10-S, (1905’12"S; 11857’36”E), depth 82 m, Coll: FRV “Soela”, CSIRO 14-Feb-1983.—one non-ovigerous $q$, one $q$ with empty marsupium, one $\hat{O}$, and one undetermined (broken), (AM P.56742), Stn 01B5-S, (1904'48"S; 118 50'48”E), depth 82 m, Coll: FRV "Soela", CSIRO 15-Feb-1983.- two SA, three nonovigerous $q$ ㅇ (one broken), and one ovigerous + , (AM P.56743), Stn 01-B12-S, (1903’30”S; 11903’30”E), depth 84 m, Coll: FRV "Soela", CSIRO 14-Feb-1983.

Redescription (partial). Cheliped (Figs 21A-C, 24A). Exopod with three articles, third article bearing four plumose setae (not illustrated). Mucus packets in carpus (Fig. 24A). Basis about 1.3 times longer than wide; ventral margin with three sub-proximal plumose setae, one spiniform seta on mid-margin, and six sub-distal plumose setae; inner face with mid-dorsal margin crenulate, with three mid-medial and three mid-dorsal simple setae (Fig. 21B). 
Merus triangular; ventral margin with small sub-proximal simple seta, mid plumose seta, and three simple setae and three translucent acute or subacute apophyses on sub-distal margin; mid-outer margin with eight plumose setae; inner face with three bipinnate spiniform setae (Fig. 21B). Carpus about twice longer than wide, larger than basis, widest distally; ventral margin with eleven plumose setae and five translucent acute or subacute apophysis; outer margin with a row of four sub-proximal plumose setae; dorsal margin with ten plumose setae, four mid setae (Fig. 21B-C), and sub-distal translucent acute or subacute apophyses; inner face with sub-distal margin having a row of 11 bipinnate setae (Fig. 21B). Propodus about 1.1 times longer than wide; ventral margin with two simple setae; outer margin with six spiniform setae (two ventral and four medial) (Fig. 21B), and two simple setae near articulation of movable finger; dorsal margin with two simple distally of unequal lengths; inner face with simple seta on outer ventral margin; with spiniform seta on mid-medial margin near articulation of movable finger, and "comb row" of nine (i.e., one biserrate and eight bipinnate) setae, and dorsal margin with sub-proximal simple seta (Fig. 21B); fixed finger with two ventral setae; with three spiniform seta and six sub-marginal simple setae on outer incisive margin, with tooth, with weakly crenulate dorsal margin after tooth, with two proximal simple setae of unequal lengths, claw short; inner face with sub-distal, ventro-lateral spiniform seta, incisive inner margin with two proximal simple setae, after tooth with row of seven small spines (Fig. 21B). Dactylus longer than fixed finger, with row of six spines ventrally (Fig. 21A); inner face with three pinnate spiniform setae on sub-distal margin (Fig. 21B).

Pereopod-1 (Figs 22, 24B). Fossorial, strongly developed, with mucus packets in basis, merus, carpus, and propodus (Fig. 24B). Coxa, excluding anterior process, sub-quadrate; ventral margin with two setulate setae, simple seta, and small denticles adjacent to base of coxal process; inner face with row of 14 simple setae (Fig. 22D); coxal process well-developed, having length about twice width, becoming distally rounded, terminating in rounded tip (Fig. 22A); ventral margin asetose (Fig. 22A); dorsal margin with eight translucent acute or subacute apophysis and seven setulate setae (Fig. 22A). Exopod with three articles, third article bearing seven plumose setae (Fig. 22B). Basis 2.3 times longer than wide; ventral margin with nine setulate setae; mid-distal outer margin with setulose seta; dorsal margin with row of seven translucent acute or subacute apophysis interspersed in row of eight setulate setae with distal-most being smaller, and sub-distal small simple seta; inner face with three (one sub-distal and two distal) small setae and distal spiniform seta on ventral margin (Fig. 22D). Ischium wider than long, with cluster of five simple setae of unequal lengths on ventral margin (Figs 22D). Merus 2.1 times longer than wide, widest distally; ventral margin with six setulate setae and sub-distal stout spiniform seta; outer margin with sub-distal dorsal simple setae; dorsal margin with a row of seven inner bipinnate spiniform setae and distal stout spiniform seta (Fig. 22AB); inner face with cluster of six setulate setae on half proximal margin, four (three setulate and one inner bipinnate spiniform) setae on half distal margin, and two distal inner bipinnate spiniform setae (Fig. 22D). Carpus 1.2 times longer than wide; ventral margin with two stout spiniform setae and three simple setae; outer dorsal margin with four (two mid and two sub-distal) inner bipinnate spiniform setae and distal stout spiniform seta; dorsal margin with two inner bipinnate spiniform setae and distal stout spiniform seta; inner face with semi-circular row of eight inner bipinnate spiniform setae of unequal lengths extending from mid-face ventrally to dorsal margin; distodorsal margin with semi-circular row of seven inner bipinnate spiniform setae being smaller ventrally (Fig. 22D). Propodus 1.1 times longer than wide, widest distally; ventral margin with three stout spiniform setae and four simple setae; outer ventral margin with two (mid and distal) simple setae; dorsal margin with mid PSS, three (two mid and one subdistal) inner bipinnate spiniform setae, and two (sub-distal and distal) stout spiniform setae; inner face with simple seta and setulate spiniform seta on distal margin (Fig. 22D). Dactylus together with unguis shorter than propodus, dactylus longer than unguis; ventral margin of dactylus with mid denticle and small distal denticle having two small fine setae (Fig. 22C), dorsal margin with small simple seta.

Pereopod-2 (Figs 23A, 24C). Longer and less robust than pereopod-1, with mucus packets in carpus and propodus (Fig. 24C). Coxa with plumose seta and translucent acute or subacute apophysis on distoventral margin; inner face with distoventral row of five simple setae. Basis about 3.9 times longer than wide; ventral margin subproximal PSS and ten plumose setae; dorsal margin with two sub-proximal PSS, three curved translucent acute or subacute apophysis, seven plumose (four very small and three long of varying lengths) setae. Ischium wider than long, distoventral margin with three simple and two plumose setae of unequal lengths. Merus about twice longer than wide, widest distally; ventral margin with five small mid plumose setae, four (one in the middle, two subdistal, and distal) simple setae, and three sub-distal stout spiniform setae; dorsal margin with one sub-proximal and two sub-distal plumose setae. Carpus about 2.4 times longer than wide; ventral margin with five simple setae and four stout spiniform setae (two in the middle and two sub-distal); outer sub-distal margin with two stout spiniform setae, outer and inner sub-distal margin with a crown of six plumose setae (one extending distally over $3 / 4$ length of 
propodus) of varying lengths. Propodus about 4.9 times longer than wide, longer than combined lengths of merus and carpus; ventral margin with five mid-bipinnate stout spiniform setae, three simple setae; outer ventral margin with three plumose setae and outer dorsal margin with sub-distal plumose seta; dorsal margin with sub-distal PSS and two sub-distal simple setae; inner margin with sub-distal simple seta. Dactylus curved, styliform, acutely tip, together with unguis slightly longer than propodus, dactylus longer than unguis; dactylus with simple seta on mid ventral margin.

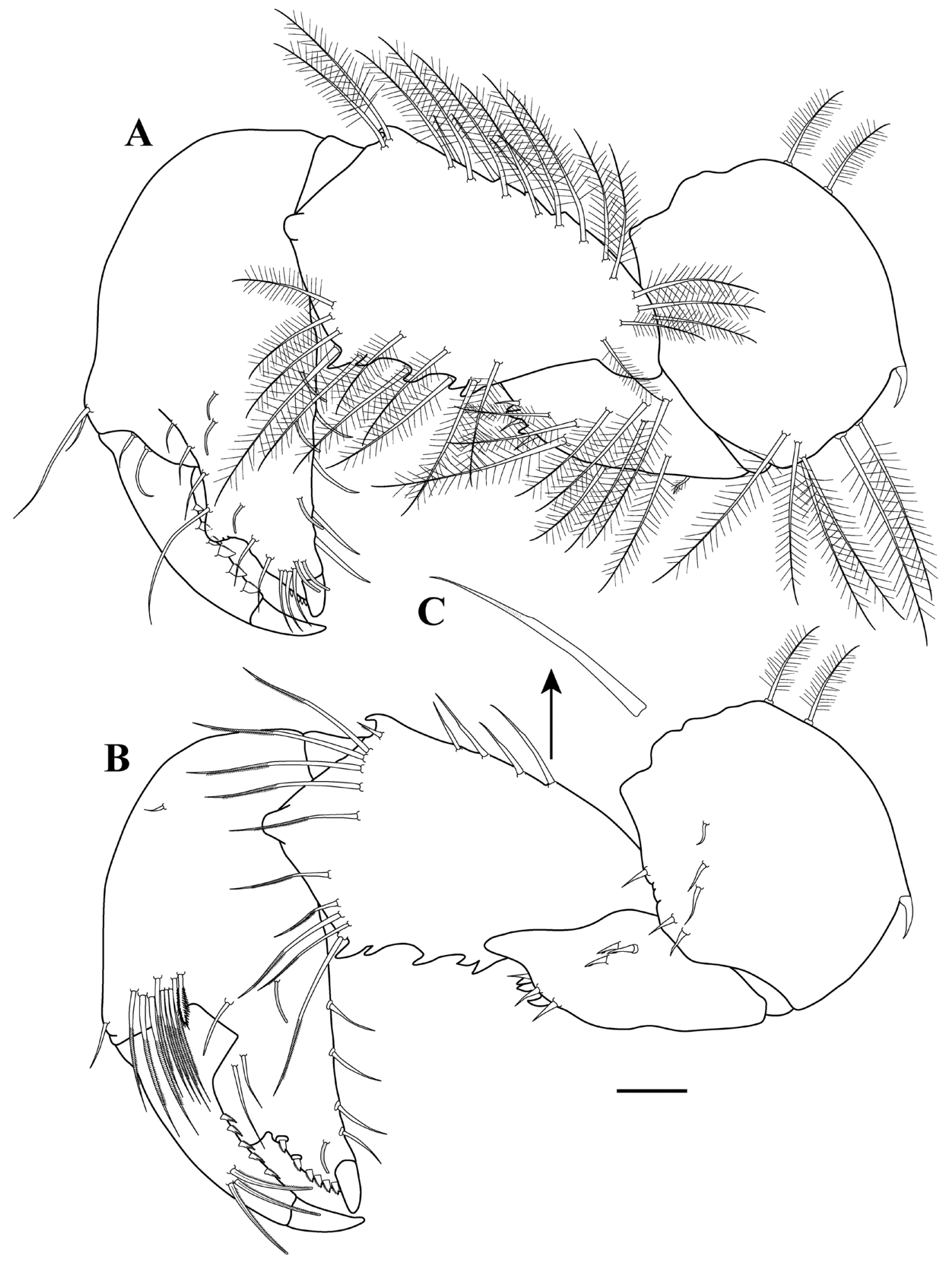

FIGURE 21. Julmarichardia gutui, topotypical non-ovigerous female (with oostegites). A, cheliped, outer view; B, cheliped, inner view; C, enlargement of seta. Scale bar $=0.1 \mathrm{~mm}$ for A-B. 

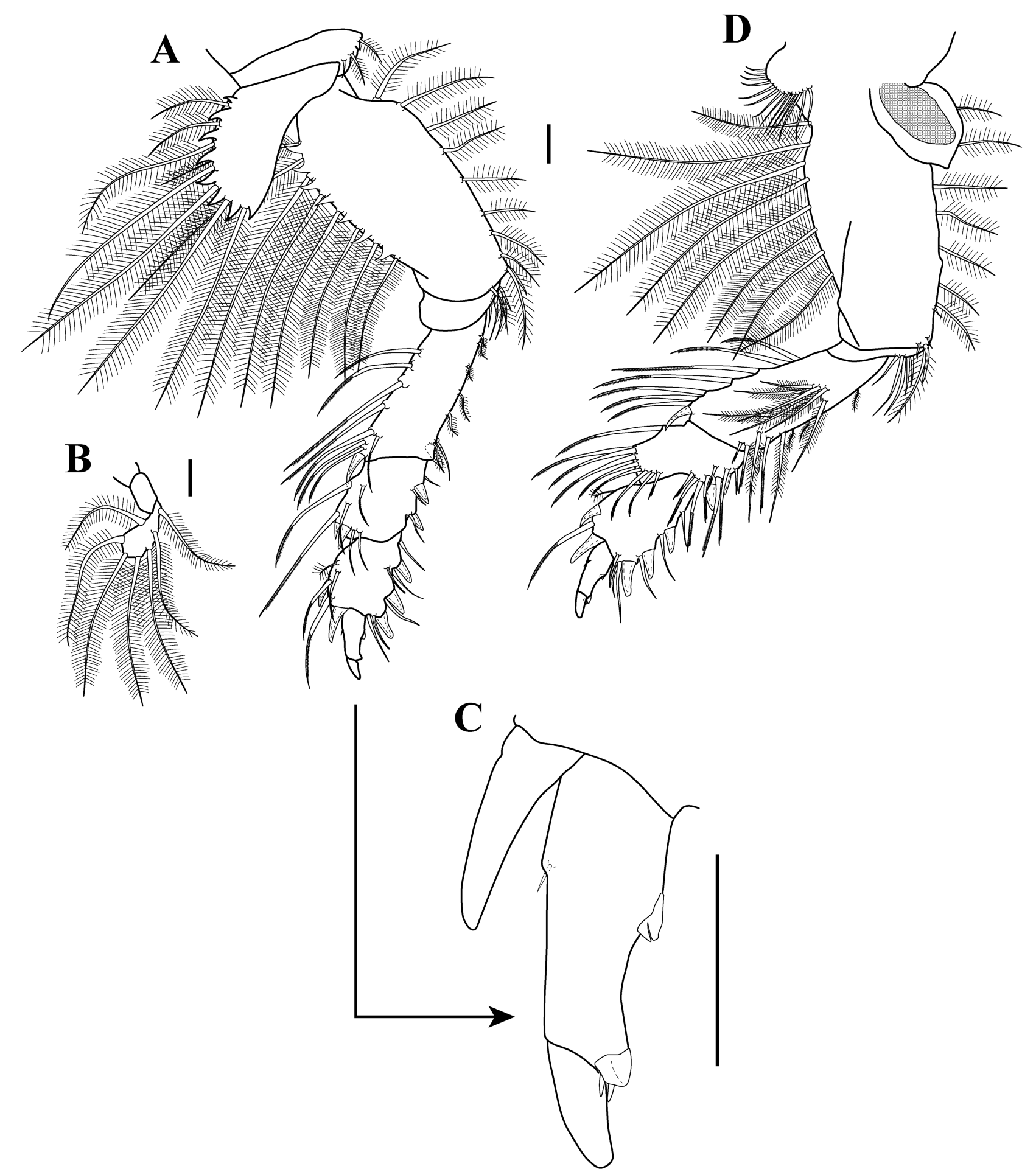

FIGURE 22. Julmarichardia gutui, topotypical non-ovigerous female (with oostegites). A, pereopod-1, outer view; B, exopod of pereopod-1; C, enlargement of dactylus and unguis; D, pereopod-1, inner view. Scale bar $=0.1 \mathrm{~mm}$.

Pereopod-3 (Figs 23B, 24D). Similar to pereopod-2, but shorter. Basis with ventral margin having eight plumose setae and one PSS on distal margin; outer margin with two plumose setae; dorsal margin with three sub-proximal PSS, one curved translucent acute or subacute apophyses, and five plumose setae. Merus distodorsal margin with plumose seta.

Intraspecific variation. Julmarichardia $(J$.) gutui exhibits some degree of variation between left and right side of the same specimen, and among the individuals examined during this study as follows: 


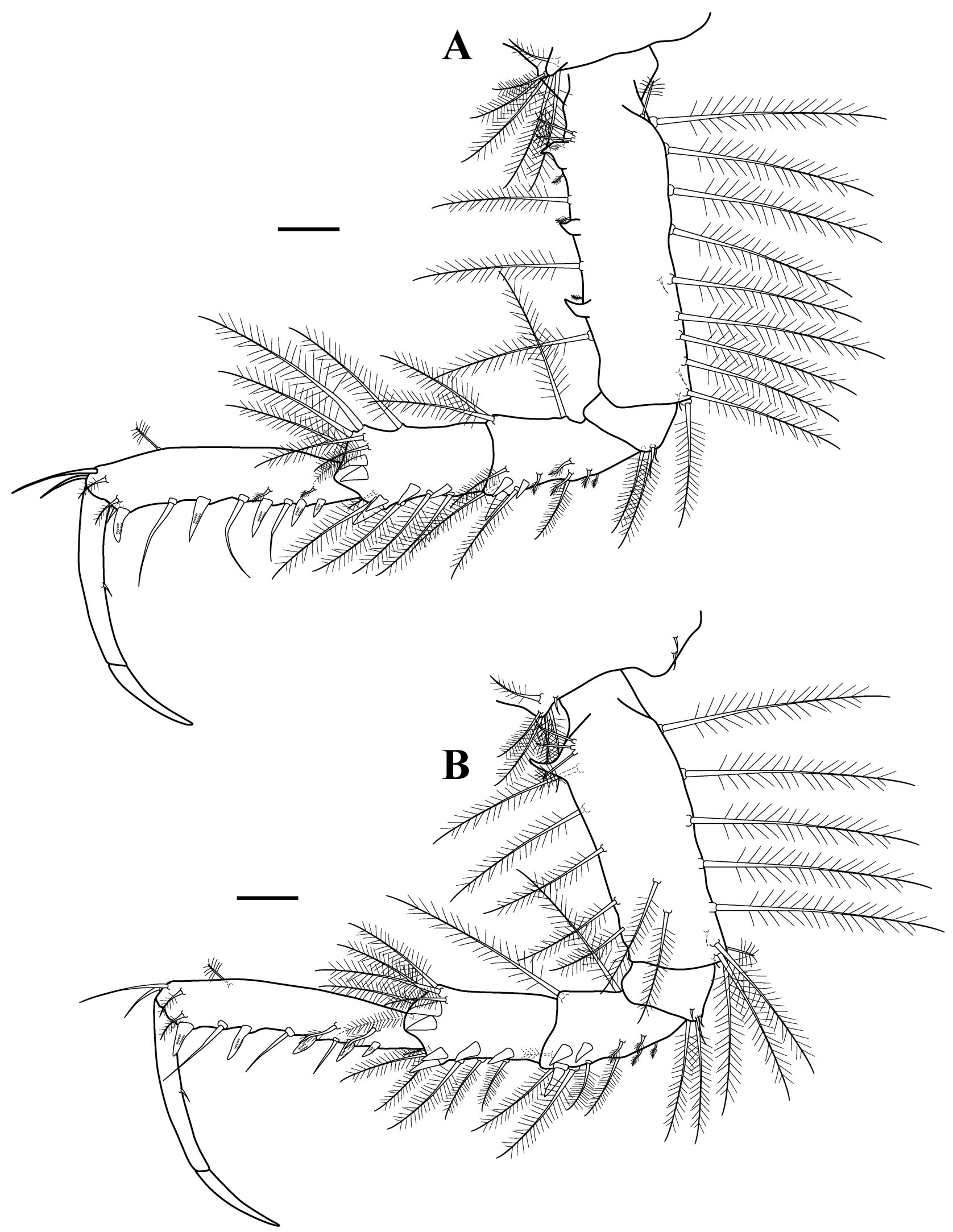

FIGURE 23. Julmarichardia gutui, topotypical non-ovigerous female (with oostegites). A, pereopod-2, outer view; B, pereopod3 , inner view. Scale bar $=0.1 \mathrm{~mm}$. 
(1) Number of articles on the antennular outer flagellum observed on non-ovigerous females varied from 9-10.

(2) Number of articles on the antenna observed on non-ovigerous females varied from 11-12.

(3) Number of spiniform setae on the ventral margin of pereopod 2-3 propodus of non-ovigerous females varied from 3-4. This number can vary between right and left side of the same specimen.

(4) Number of bipinnate spiniform setae occurring in the inner view of merus of cheliped varied from 2-3.

Size-distribution. The non-ovigerous females ranged from 3.3 to $4.9 \mathrm{~mm}(\mathrm{n}=10)$. Ovigerous females varied from 3.4 to $4.0 \mathrm{~mm}(\mathrm{n}=3)$. Adult males ranged from 3.3 to $3.6 \mathrm{~mm}(\mathrm{n}=4)$.
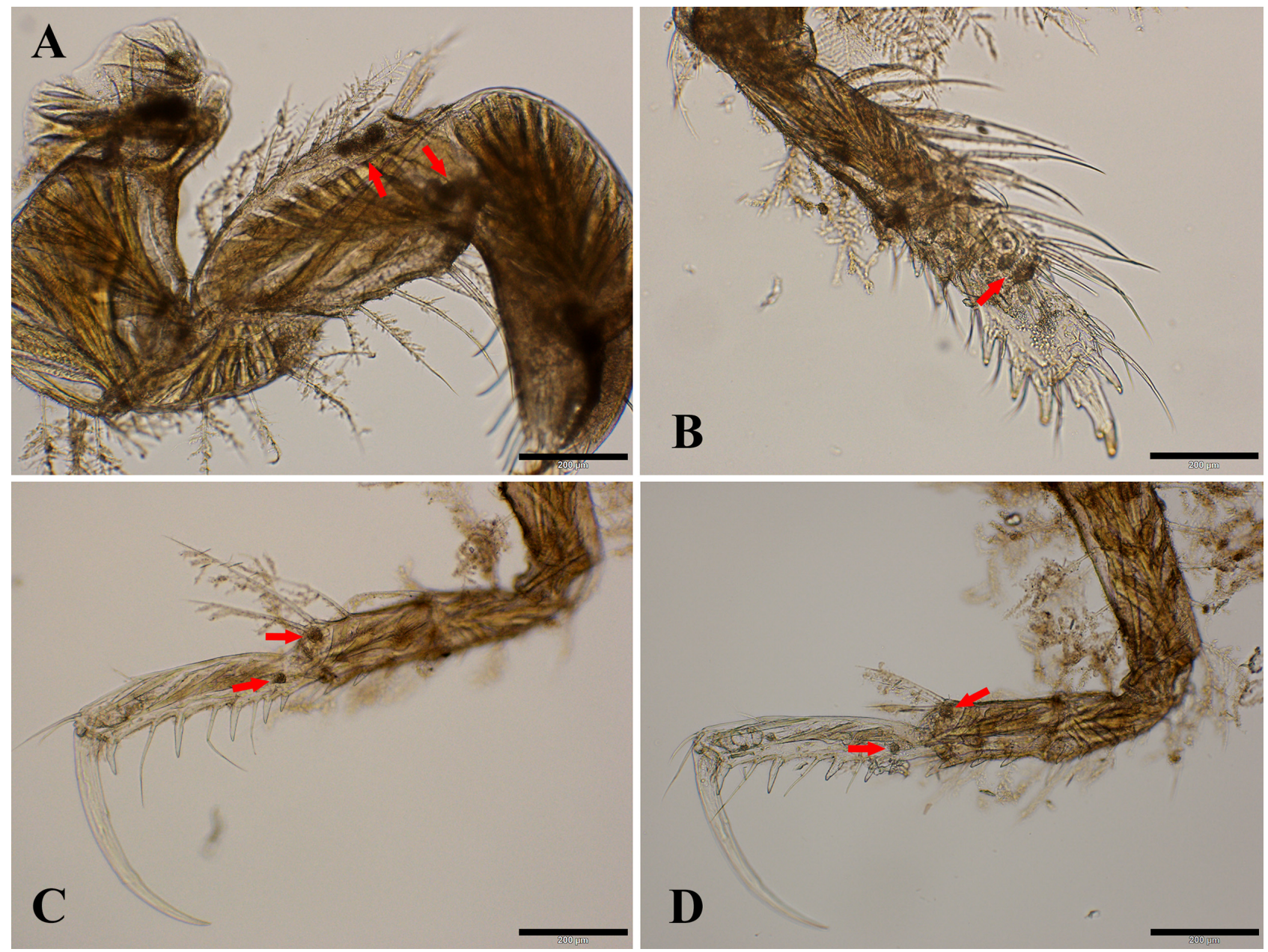

FIGURE 24. Digital images of Julmarichardia gutui topotypical non-ovigerous female (with oostegites). A, cheliped, outer view, B, pereopod-1, outer view; C, peropod-2, outer view; D, pereopod-3, outer view. Red arrows shown the presence of mucus packets. Scale bars $=0.2 \mathrm{~mm}$. Photos by A.G. Morales-Núñez.

Remarks. Upon reexamination of paratypes and additional material used in the description of $J$. gutui, we found several discrepancies in its original description. These include: (1) the presence of a cluster/row of plumose setae (smaller mid-dorsally and increasing in size mid-laterally) on the mid-dorsolateral margin of the carapace of both sexes, but fewer present on males (illustrated but not included under the original description); (2) overall female cheliped with more plumose setae; (3) cheliped exopod with three articles; (4) female cheliped .merus having two translucent acute or subacute apophyses on sub-distal margin; (5) female cheliped inner margin of merus bearing three bipinnate spiniform setae; and (6) female cheliped .carpus having five translucent acute or subacute apophysis on ventral margin. 


\section{Julmarichardia sp. A}

(Figs 20B, 20H, 25)

Material examined. One $q$ with oostegites, TBL $2.7 \mathrm{~mm},\left(\right.$ AM P.52212), Stn 06-B7-S, (19²2’00”S; $\left.118^{\circ} 56^{\prime} 00^{\prime \prime} \mathrm{E}\right)$, depth 54 m, Coll: FRV “Soela", CSIRO 08-December-1983.

Description (partial). Body (Fig. 25A). Dorso-ventrally flattened, TBL $2.7 \mathrm{~mm}$, about 4.5 times width.

Cephalothorax (Fig. 25A). About $\sim 20 \%$ of TBL, as long as wide, shorter than combined lengths of pereonites 1-3; rostrum well-developed, spatulate, deflected anteroventrally, margins entire, smooth lacking small denticles and setulate setae (Fig. 25A-C); eyes-lobes well defined, pointed, visual elements present. Carapace without row of small spines at basis of rostrum, without small denticles at basis of antennule, without setulate setae along middorsal margin (Fig. 25A-C).

Pereon (Fig. 25A). About $\sim 50 \%$ of TL, all pereonites wider than long, each with antero-posterior lateral margins having very small denticles; pereonite- 1 widest; pereonite-4 longest; pereonite-6 shortest; pereonites $1-6$ each with one to three setulate setae on proximal and distal margins; pereonites 1-5 with two small setulate setae on middorsally.

Pleon (Fig. 25A). About $\sim 20 \%$ of TL, combined lengths of pleonites 1-5 longer than pereonites 5-6; all pleonites sub-equal, wider than long, bearing pleopods; each pleonite with lateral margins armed with denticulate triangulate-like lateral process bearing several plumose setae at or near apex; each pleonite with plumose seta on lateral margins; pleonites 1-4 with four (two proximal and two distal) small simple setae on mid-dorsal margin; pleonite-5 with two plumose setae on disto mid-dorsal margin.

Pleotelson (Fig. 25A). About $\sim 10 \%$ of TBL, longer than pereonite-6; sub-distal anterior dorsolateral margin with two small plumose setae, with four plumose setae on sub-distal posterior dorsal margin, with dorso sub-distal plumose seta close to the insertion with uropod at each site, with small rounded apical lobe; antero-laterally with narrow apophysis bearing plumose seta on dorsal margin and plumose seta distally, and postero-laterally apophysis bearing plumose seta.

Antenna (Figs 20B, 25D-E). With ten articles, distinctly shorter than antennule. Article-1 (not illustrated) with prominent spatulate process on inner margin. Article-2 about 2.9 times longer than wide; inner dorsal margin with $\sim 12$ translucent acute or subacute apophyses of varying lengths (Fig. 25E) and three plumose setae (not illustrated); inner ventral margin with proximal rounded process (beneath the spatulate process of article-1) bearing three plumose setae, with $\sim$ six translucent acute or subacute apophyses of varying lengths, and three plumose setae (Fig. 25D); outer distodorsal margin with small simple seta; squama present, longer than article-3, with three distal simple setae of varying lengths. Article-3 1.5 times longer than wide, inner distal margin with long simple seta. Article-4 about 1.8 times longer than wide; inner sub-distal margin with plumose seta. Article-5 about 3.7 times longer than wide, slightly shorter than articles 3-4 combined; inner margin with long simple seta and PSS; mid and sub-distal margins with one PSS; outer distal margin with two PSS. Article-6 short, asetose. Article-7 about 2.4 times longer than wide; inner margin with distal simple seta. Article-8 about 3.7 times longer than wide; mid inner margin with PSS; outer distal margin with simple seta and PSS. Article-9 same length than article-8; inner distal margin with simple seta; medial distal margin with simple seta; Article-10 same length as article-9, with four distal setae of varying lengths.

Pereopod-1 (no illustrated). Fossorial, strongly developed, with mucus packets in merus, carpus, and propodus. Coxa, excluding anterior process, sub-quadrate; distoventral margin with four small simple setae and small denticles adjacent to base of coxal process; distodorsal margin with simple seta and translucent rounded apophysis; inner face with row of ten simple setae; coxal process well-developed, triangular, having length about twice width, becoming distally attenuated, terminating in acute tip; ventral margin asetose; dorsal margin with four translucent acute or subacute apophyses and four setulate setae, distal most buttressed and largest. Exopod with three articles, third article bearing six plumose setae.

Remarks. The adult female of Julmarichardia sp. A available for this study in most aspects resembles those of $J$. gutui and $J$. magdae by having a rostrum well-developed, spatulate, and deflected anteroventrally. However, Julmarichardia sp. A closely resembles $J$. magdae by having the pereopod-1 with an acute coxal process. Julmarichardia sp. A, , is also distinct from J. gutui, J. magdae, and other members of the genus by having the margins of its rostrum entire and smooth, lacking small denticles and/or setulate setae characteristic of these others.

We considered describing Julmarichardia sp. A as a new species because of its apparent unique combination of characters exhibited. However, since only a single specimen was found exhibiting these features, we cannot confirm 
whether Julmarichardia sp. A belongs to an undescribed species or if the lack of the rostral denticles and/or setulate setae is an abnormality or the result of recent moulting. Nevertheless, the distribution of J. magdae, Julmarichardia sp. A, and $J$. gutui suggests the possibility of additional species of the genus may be segregated along the shallower or deeper depth and sediment gradients across the NW Australian Continental Shelf.

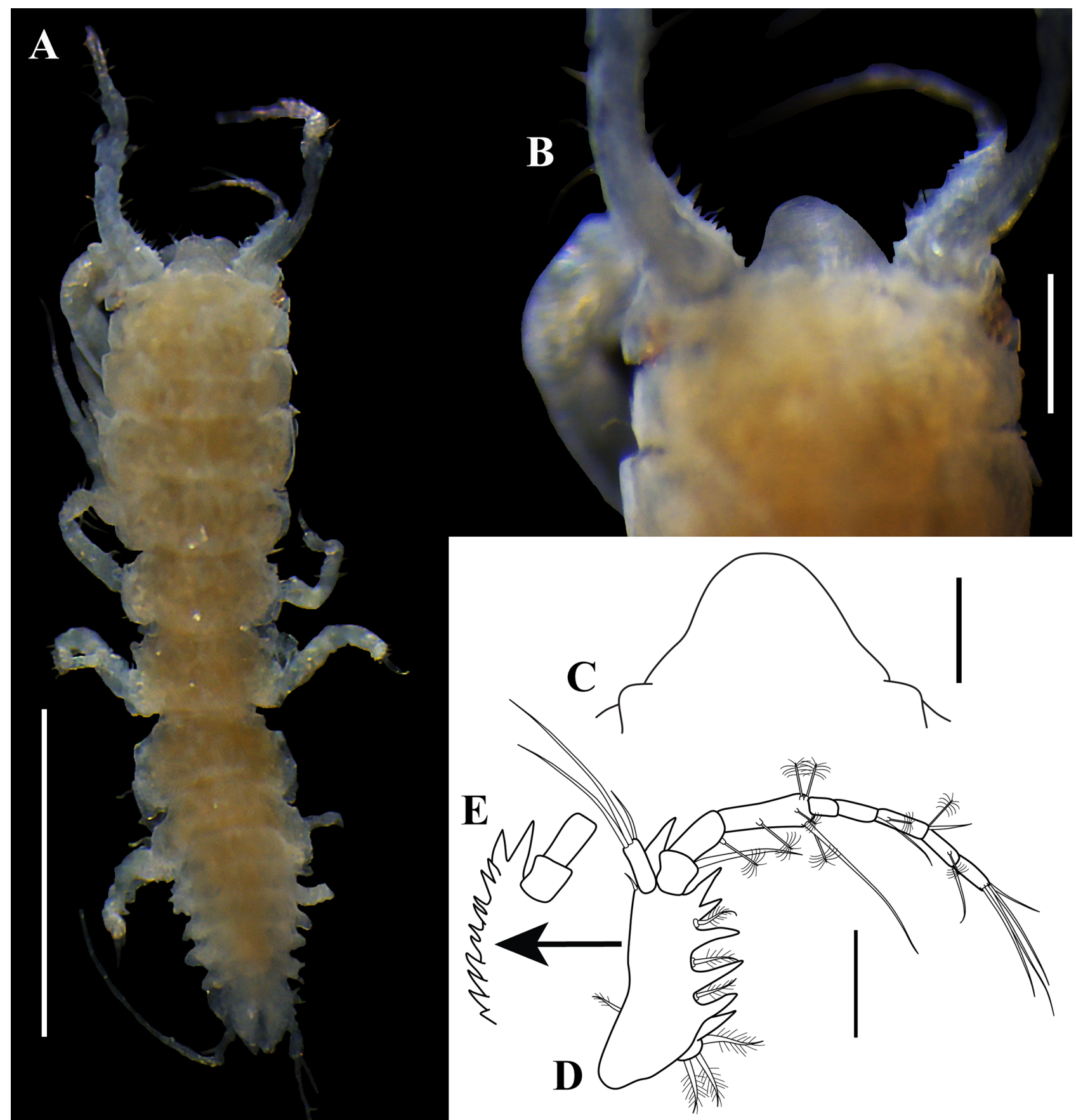

FIGURE 25. Digital images of Julmarichardia sp. A, female with oostegites: A, dorsal view of habitus, length 2.7 mm; B, enlargement of anterior end. C, rostrum, dorsal view; D, antenna; E, antenna inner dorsal margin. Scale bar $=1.0 \mathrm{~mm}$ for A and $0.1 \mathrm{~mm}$ for B-E. Photos by A.G. Morales-Núñez.

\section{Key to the known adult females of the genus Julmarichardia, modified from Ritger \& Heard (2007)}

1. Antenna with article-2 lacking distinct marginal spines or tubercles (Fig. 20A).

$\ldots \ldots \ldots \ldots \ldots \ldots \ldots \ldots \ldots \ldots \ldots \ldots \ldots \ldots \ldots \ldots \ldots \ldots \ldots$ Richardjulmaia bajau Bamber \& Sheader, 2005 gen. nov.

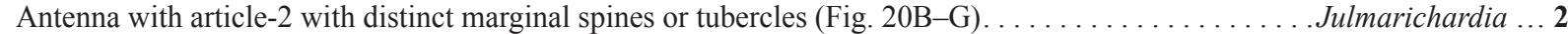

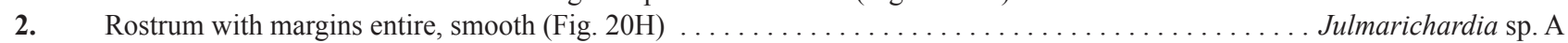




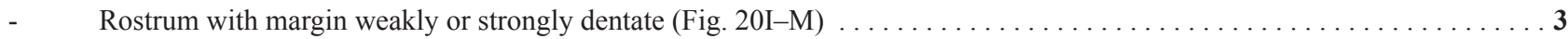

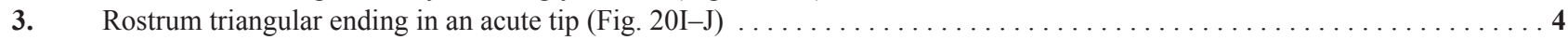

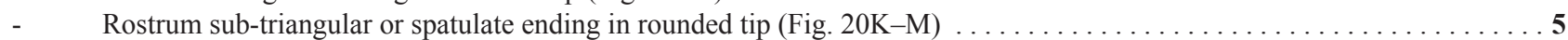

4. Rostrum strongly denticulate laterally, having 12-14 acute marginal teeth (Fig. 20I) . . . . . . . . . . . . J. alinati Guţu, 1989

- $\quad$ Rostrum not strongly denticulate laterally, having 6-7 regular marginal teeth on mid-margin (Fig. 20J) . . . . . . . . . . .

. Jeltoides (Barnard, 1914)

5. Rostrum sub-triangular ending in rounded tip (Fig. 20K) . . . . . . . . . . . . . . . . . . . . . J. thomassini Guţu, 1989

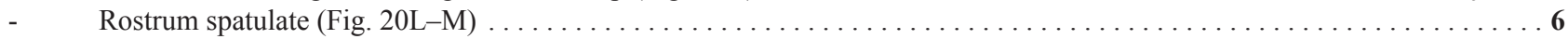

6. Rostrum with 8-20 long marginal plumose setae (Fig. 20L). Pereopod-1 with subacute coxal process armed with 5-6 translucent acute or subacute apophyses and $4-5$ plumose setae (Fig. 20N) . . . . . . . . . . . . . . J. gutui Ritger \& Heard, 2007 Rostrum lacking long marginal plumose setae (Fig. 20M). Pereopod-1 with acute coxal process armed with 4-5 denticles and

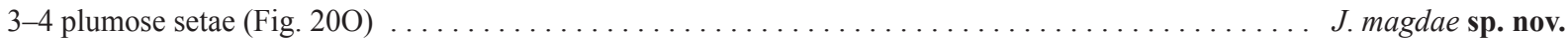

\section{Discussion}

Possibly due to being overlooked and the little attention that tube construction in Tanaidacea has received, the presence of mucus glands and tube-like domiciles (such as here in the julmarichardiids) have not been widely reported, but has been documented for the apseudomorphan families Kalliapseudidae, Parapseudidae, and Numbakullidae. Nonetheless, recently, this kind of gland and tube-like domiciles has been reported for Phoxokalliapseudes tomiokeensis (Shiino, 1966) and Brachylicoa lui Morales-Núñez, Ulrich \& Heard, 2017 (Kakui \& Hiruta 2014; Morales-Núñez et al. 2017, respectively). We also have observed similar glandular structures in an unidentified species belonging to the parapseudid genus Pseudoapseudes Guţu, 1981 from the Gulf of California (RW. Heard, AG. Morales-Núñez, per. observ.). Additionally, a novel pleotelsonal gland system in a parapseudid (Parapseudes algicola) was discovered and reported by Kakui \& Hiruta (2017). The distribution of the mucus packets stored found in Julmarichardia magdae is quite different to the three (i.e., thoracic-gland system, pereopodal-gland system, and pleotelsonal gland system) secreting systems in Tanaidacea reported and described by Kakui \& Hiruta 2017, because, in J. magdae the mucus packets were observed on the antennule, antenna, pereopods, and pleotelson at the same time. To emphasize, this is the first time that these glands are reported from the antennule and antenna of Tanaidacea.

Unlike those known for the other metapseudid genera, species within the family Julmarichardiidae (e.g., Julmarichardia alinati, J. gutui, J. magdae, J. thomassini, and sp. A) have more glands and numerous mucus packets stored throughout its body (Table 1). During this study, we noticed that most instances it was difficult to observe the presence and determined number of the translucent acute/subacute apophyses present in several parts of the body of J. magdae, J. gutui, and Julmarichardia sp. A., especially on the chelipeds and pereopods, because they were covered by the plumose setae. This suggested that the presences of these apophyses may have been similarly obscured and overlooked, during the description of the other species of the family.

\section{Acknowledgments}

We thank Penney Barents, and Jim K. Lowry of the Australian Museum, Sydney, for allowing us access to the material used in this study. Stephen Keable (Australian Museum) kindly provided additional collection data for the material examined. We are most grateful to Modest Guţu (Travaux du Muséum National d'Histoire Naturelle "Grigore Antipa") for reexamining the type material of Julmarichardia alinati and J. thomassini. We wish to extend our gratitude to Juliana Segadilha, Graham J. Bird, and one anonymous reviewer for their thoughtful and constructive comments, which have improved the quality of the paper. We take full responsibility for any differing systematic or taxonomic opinions and interpretations.

\section{Compliance with ethical standards}

Funding: AGM-N was supported by NSF-CREST Center for the Integrated Study of Coastal Ecosystem Processes and Dynamics in the Mid-Atlantic Region (CISCEP) grants numbers. 1036586 and 1547821. 
Conflict of Interest: The authors declare that they have no conflict of interest.

Ethical approval: All applicable international, national, and/or institutional guidelines for the care and use of animals were followed by the authors.

Sampling and field studies: Permits and approval for sampling and observational field are not applicable for authors.

\section{References}

Bamber, R. \& Sheader, M. (2005) Apseudomorph Tanaidacea (Crustacea: Peracarida) from shallow waters off Sabah, Malaysia. Systematics and Biodiversity, 26 (3), 281-303. https://doi.org/10.1017/S1477200004001495

Barnard, K.H. (1914) Contributions to the crustacean fauna of South Africa. 3. Additions to the marine Isopoda with notes on some previously incompletely known species. Annals of the South African Museum, 10 (11), 325a-442a + 358a-440. https://doi.org/10.5962/bhl.part.9319

Bird, G.J. (2011) Paratanaoidean tanaidaceans (Crustacea: Peracarida) from littoral and shallow sublittoral habitats in New Zealand, with descriptions of three new genera and seven new species. Zootaxa, 2891 (1), 1-62. https://doi.org/10.11646/zootaxa.2891.1.1

Drumm, D.T. (2005) Comparison of feeding mechanisms, respiration, and cleaning behavior in two kalliapseudids, Kalliapseudes macsweenyi and Psammokalliapseudes granulosus (Peracarida: Tanaidacea). Journal of Crustacean Biology, 25 (2), 203 211. https://doi.org/10.1651/C-2524

Gutu, M. (1981). A new contribution to the systematics and phylogeny of the suborder Monokonophora (Crustacea, Tanaidacea). Travaux du Muséum National d'Histoire Naturelle "Grigore Antipa". 23, 81-108.

Guţu, M. (1989a) Tanaidacea (Crustacea) collected by the "Benthédi” French Expedition (1977) in the Southwestern Indian Ocean. Travaux du Musée d'Histoire naturelle "Grigore Antipa”, 30, 135-160.

Guţu, M. (1989b) La description de Calozodion dollfusi, espèce nouvelle de tanaïdacés (Crustacea) provenant des eaux européennes de 1'Atlantique. Travaux du Muséum National d'Histoire naturelle "Grigore Antipa”, 30, 129-133.

Guţu, M. (2014) Two new species of the genus Calozodion Gardiner (Crustacea: Tanaidacea: Apseudomorpha) from the Adriatic Sea and the Indian Ocean, and the reclassification of C. dollfusi Guţu, 1989 in the genus Julmarichardia Guţu. Travaux du Muséum National d'Histoire Naturelle "Grigore Antipa”, 57 (1), 13-26. https://doi.org/10.2478/travmu-2014-0002

Guţu, M. \& Heard, R. W. (2002) A new genus and species of a new family of tanaidaceans (Crustacea: Peracarida) from Australian waters. Travaux du Muséum National d'Histoire Naturelle "Grigore Antipa”, 46, 93-103.

Heard, R.W., Hansknecht, T. \& Larsen, K. (2004) An illustrated Identification Guide to Florida Tanaidacea (Crustacea: Peracarida) occurring in depths of less than $200 \mathrm{~m}$. Florida Department of Environmental Protection. Division of Water Resource Management, Tallahassee, Florida, 163 pp. Available from: http://publicfiles.dep.state.fl.us/dear/labs/biology/ biokeys/tanaidacea.pdf (accessed 13 November 2021)

Heard, R. W., Stępień, A., Drumm, D. T., Błażewicz, M., Anderson, G. (2018) Systematic and taxonomic observations on the subfamily Synapseudinae Guţu, 1972 and related metapseudid taxa (Crustacea: Tanaidacea: Apseudomorpha), with the erection of a new genus and descriptions of three new species. Zootaxa, 4370 (4), 301-344. https://doi.org/10.11646/zootaxa.4370.4.1

Kakui, K. \& Hiruta, C. (2014) Diverse pereopodal secretory systems implicated in filament production in an apseudomorph tanaidacean crustacean. Journal of Morphology, 275, 1041-1052. https://doi.org/10.1002/jmor.20281

Kakui, K. \& Hiruta, C. (2017) Tube construction by a tanaidacean crustacean using a novel mucus secretion system involving the anal opening. Zoological Letters, 3 (1), 1-7. https://doi.org/10.1186/s40851-017-0082-7

Lang, K. (1956). Kalliapseudidae, a new family of Tanaidacea. In: Wingstrand, K.G. \& Hanström, B (Eds.), Zoological Papers in Honour of his Sixty-fifth Birthday, November 20th, 1956. Zoological Institute, Lund, pp. 205-225.

Lang, K. (1970) Taxonomische und phylogenetische Untersuchungen über die Tanaidaceen 4. Aufteilung der Apseudiden in vier Familien nebst aufstellung von zwei Gattungen und einer Art der neuen Familie Leiopidae. Arkiv för Zoologi, Series 2, 22 (16), 595-626.

Larsen, K. (2003) Proposed new standardized anatomical terminology for the Tanaidacea (Peracarida). Journal of Crustacean Biology, 23 (3), 644-661. https://doi.org/10.1651/c-2363

Morales-Núñez, A.G., Ulrich, S., \& Heard, R.W. (2017) Brachylicoa lui a new species of parapseudid tanaidacean (Crustacea: Peracarida: Apseudomorpha), from the Hawaiian Islands, with a taxonomic key. Zoosystematics and Evolution, 93 (2), 413-435. https://doi.org/10.3897/zse.93.13824

Ritger, R.K. \& Heard, R.W. (2007) Julmarichardia gutui, a new species of Apseudomorph Tanaidacean (Crustacea: Malacostraca: 
Peracarida) from the Australian Northwest Continental Shelf. Zootaxa, 1559 (1), 59-68.

https://doi.org/10.11646/zootaxa.1559.1.3

Stępień, A. (2013) A new species of Numbakullidae Guţu \& Heard, 2002 (Tanaidacea, Peracarida, Crustacea) from the Great Barrier Reef, Australia. Zookeys, 337, 35-47.

https://doi.org/10.3897/zookeys.337.5903 